\title{
Breves notas en torno a la legitimidad para obrar activa de la Administración tributaria y el artículo 157 del Código Tributario ${ }^{(*)}(*)$
}

\section{Brief notes on the standing to act of the Tax Administration and Article 157 of the Tax Code}

\author{
Percy Enrique Bardales Castro(**) \\ Ernst \& Young Perú (Lima, Perú)
}

\begin{abstract}
Resumen: El presente documento pretende abordar, en un primer momento, el tratamiento legislativo que ha tenido en el tiempo el artículo 157 del Código Tributario, en relación con la posibilidad que la Administración Tributaria pueda impugnar en la vía del proceso contencioso administrativo las resoluciones que emite el Tribunal Fiscal. Sobre esa base, en un segundo momento se analizará los alcances normativos de esta materia a partir del texto vigente del artículo 157 del Código Tributario.
\end{abstract}

Palabras clave: Derecho Tributario - Administración Tributaria - Artículo 157 del Código Tributario - SUNAT - Proceso contencioso-administrativo tributario - Proceso de lesividad - Legitimidad para obrar activa - Legitimidad para obrar activa ordinaria - Legitimidad para obrar activa extraordinaria - Perú

\begin{abstract}
This document intends to address, at first, the legislative treatment that article 157 of the Tax Code has had over time, in relation to the possibility that the Tax Administration may challenge the resolutions issued by the Tax Court through the contentious-administrative process. On this basis, in a second stage, the normative scope of this matter will be analyzed based on the current text of article 157 of the Tax Code.

Key words: Tax law - Tax Administration - Article 157 of the Tax Code - Contentiousadministrative tax proceedings - Litigation proceedings - Legitimacy to take active action - Legitimacy to take ordinary active action - Legitimacy to take extraordinary active action - SUNAT - Peru
\end{abstract}

(*) Nota del Equipo Editorial: Este artículo fue recibido el 28 de mayo de 2021 y su publicación fue aprobada el 2 de setiembre de 2021.

$\left(^{* *}\right.$ Las opiniones vertidas en el presente documento son de exclusiva responsabilidad del autor.

${ }^{(* *}$ ) Abogado por la Pontificia Universidad Católica del Perú (PUCP). MBA por la Universidad Adolfo Ibáñez (Chile). Postítulo en Derecho Procesal Constitucional por la Pontificia Universidad Católica del Perú. Especialización en Derecho - Programa en Derecho Constitucional Tributario por la Universidad de Salamanca (España). Especialización Avanzada en Derecho Penal y Procesal Penal por la PUCP. Miembro del Instituto Peruano de Derecho Tributario (IPDT) y de la Asociación Fiscal Internacional (IFA) Perú. Socio de EY (Ernst \& Young). Autor de diversas publicaciones en materia tributaria. ORCID: https://orcid.org/0000-0002-4123-9398. Correo electrónico: percy.bardales@pe.ey.com. 


\section{A modo de introducción}

Actualmente, y desde ya hace varios años, no existe duda de que la agenda fiscal se discute en el Poder Judicial. Es decir, es a nivel de esta instancia, en especial a nivel de la Corte Suprema de Justicia, que se discuten y resuelven las controversias tributarias más relevantes del país.

Varios factores han contribuido a que la agenda fiscal se discuta a nivel del Poder Judicial. Así, entre otros, se encuentra: (i) la creación de los Juzgados y Salas Superiores Especializados en lo Contencioso Administrativo, con SubEspecialidad en Temas Tributarios y Aduaneros ${ }^{(1)}$; (ii) la -consecuente- judicialización de la tributación (por ejemplo., a nivel de la justicia ordinaria y constitucional); (iii) la discusión y resolución -en último grado y sobre el fondo de la controversia- de los temas relevantes de la agenda fiscal actual en las Cortes (ejemplo, Corte Suprema de Justicia, Tribunal Constitucional); (iv) la -saludable- profundización e interiorización cada vez mayor por parte de la sociedad sobre el enfoque constitucional -frente a la legalidad ordinaria- de la tributación; (v) la -consecuente y necesaria- exigencia de redimensionamiento de los roles, reglas y límites aplicables a la funcionalidad de la tributación (por ejemplo, fiscalización, determinación, imposición de sanciones, cobro, colaboración de terceros, entre otros aspectos); (vi) el -expectante- rol y fuerza de los medios de información sobre el impacto de la tributación; y, sin lugar a dudas; y (vii) la participación activa y permanente de la Administración Tributaria( ${ }^{(2)}$, en calidad de parte demandante, en la impugnación de Resoluciones del Tribunal Fiscal en la vía del proceso contencioso administrativo.

En relación al rol activo que ha tenido y tiene la Administración Tributaria actualmente en los procesos contenciosos administrativos -en calidad de demandante en la vía judicial-, es importante advertir que este ha respondido básicamente al rol de protección y cumplimiento del deber de contribuir por parte de todos los contribuyentes (como siempre se alega en este tipo de procesos, para quienes litigamos judicialmente en materia tributaria en el día a día, más allá de la discusión concreta de los reparos o conceptos en controversia).

Nótese, a este efecto, que los alcances del deber de contribuir deben ser analizados, entendidos y aplicados en función a su configuración en cada ordenamiento jurídico (y sistema jurídico en el que se encuentra adscrito) en concreto. En otros términos, el deber de contribuir no puede ser analizado, configurado y, por tanto, exigirse su cumplimiento (por ejemplo, no solo para la producción normativa, sino también para su fase aplicativa, con motivo del ejercicio de las potestades otorgadas), en función a un poder de imperio -y consecuente estado de sujeción-, irrestricto o absoluto (Fernández, 1995, p. 31); (Escribano, 2009, p. 449 y ss.), o simplemente a una máxima general y/o moral ${ }^{(3)}$. Su reconocimiento y protección jurídica, entonces, es y debe ser correlato estricto de lo que establece el orden constitucional y legal de cada país. En ese sentido, se ha señalado que:

[N]o existe, se mire como se mire, un deber de contribuir que sea algo adicional a la sujeción al ordenamiento jurídico. (...) El deber tributario de los ciudadanos no es otra cosa que el deber de sujeción a las leyes y al ordenamiento, es decir, al Derecho. El ciudadano, en esta, como en las demás materias, no tiene más que obligaciones que surgen de la Ley y del ordenamiento, y no deberes concretos nacidos de una genérica sumisión a la Administración Tributaria. Y la Administración no tiene, en esta materia como en cualquier otra, más facultades que las que proceden de la Ley y el ordenamiento, es decir, del Derecho, y que ninguna que emane, para situaciones concretas y sujetos concretos, de unas "potestades tributarias" de los órganos

(1) Mediante el artículo 1 de la Resolución Administrativa 206-2012-CE-PJ, publicada en el Diario Oficial EL Peruano el 27 de octubre del 2012, se dispuso la creación de: (i) los Juzgados Décimo Octavo, Décimo Noveno, Vigésimo, Vigésimo Primero, Vigésimo Segundo y Vigésimo Tercero Especializados en lo Contencioso Administrativo, con subespecialidad en temas tributarios y aduaneros; (ii) la Sexta y Sétima Salas Superiores Especializadas en lo Contencioso Administrativo, con subespecialidad en temas tributarios y aduaneros; y, (iii) el Décimo Primer Juzgado Especializado en lo Constitucional, con subespecialidad en temas tributarios y aduaneros. Mediante el artículo 1 de la Resolución Administrativa 102-2013-CE-PJ, publicada en el Diario Oficial El Peruano el 21 de junio de 2013 , se dispuso la entrada en funcionamiento de los Juzgados y Salas Especializadas en lo Contencioso Administrativo y Constitucional antes indicados, a partir del 16 de julio de 2013.

(2) Por Administración Tributaria, entiéndase legalmente, no solo el supuesto referido a la SUNAT, sino también -por ejemplo-, a las Administraciones Tributarias Locales. Para efectos del presente trabajo, empero, el análisis de la legitimidad para obrar activa de la Administración Tributaria se va a centrar en la SUNAT.

(3) Ya en el año 1776, se indicaba que "[l]os ciudadanos de cualquier Estado deben contribuir al sostenimiento del Gobierno, en cuanto sea posible, en proporción a sus respectivas aptitudes, es decir, en proporción a los ingresos que disfruten bajo la protección estatal" (Smith, 2012, p. 58) 
administrativos, capaces de ser "fuentes de facultades" distintas de la Ley, o sea, del ordenamiento (García, 1998, pp. 104-105)(4)(5).

En este contexto, en el presente artículo vamos a centrar nuestro análisis en la normativa tributaria vigente que regula la posibilidad que la Administración Tributaria cuestione judicialmente las actuaciones administrativas mediante el correspondiente proceso contencioso administrativo. Sobre esa base, vamos a establecer los alcances que, en nuestra opinión, prevé nuestra legislación actual para la legitimidad para obrar activa de la Administrativa Tributaria para impugnar Resoluciones del Tribunal Fiscal en la vía del proceso contencioso administrativo.

Para este efecto, abordaremos el tema, entre otras variables, desde un punto de vista: (i) histórico, mostrando el tratamiento normativo que ha tenido en el tiempo el régimen normativo previsto en el artículo 157 del Código Tributario vigente, en relación a la legitimidad para obrar activa de la Administrativa Tributaria, desde su inicio hasta la fecha; (ii) sistemático, en atención a la interpretación coherente que se debe establecer sobre esta materia; (iii) de la ratio legis de las normas, esto es, del fundamento de la institución jurídica y de la norma involucrada en cada aspecto; (iv) literal, en tanto que se va a referenciar los parámetros expresos que establece la normativa nacional para el control judicial de las actuaciones administrativas por la Administración Tributaria; (v) funcional, en atención a la operatividad real de la normativa tributaria involucrada en el tema materia de análisis; (vi) constitucional, situación que supone un análisis e interpretación de las normas tributarias no solo conforme a la ley, sino conforme a la prevalencia de la Constitución Política; y, lo más importante; (vii) lógico, esto es, evidenciando una estructura secuencial, estructurada y motivada de ideas que permiten llegar a una conclusión, en cada aspecto analizado, conforme a lo previsto en nuestro sistema jurídico.

Entender la normativa relativa a la legitimidad para obrar activa de la Administración Tributaria es de la mayor relevancia, porque en función al alcance material que se otorgue a la potestad administrativa para la impugnación de las Resoluciones del Tribunal Fiscal, se podrá establecer: (i) qué tipo de legitimidad para obrar activa tiene otorgada la autoridad tributaria; y, (ii) si está habilitada legalmente o no para formular pretensiones de control de legalidad, de plena jurisdicción, o ambas. Los efectos y su importancia se aprecian a la vista.
Es importante dejar constancia de que esta experiencia académica se inició, partiendo de la premisa de que en materia tributaria -en estricto, en cualquiera materia en generalla argumentación de ideas es positiva, toda vez que nos permite comprender la correspondencia de la ley al orden constitucional y social del momento, y la utilidad práctica de las instituciones jurídicas reguladas por el legislador. Reconociendo también, empero, que la argumentación jurídica genera la reacción del operador jurídico para definir a futuro una línea de cambio, el ánimo que mueve el presente trabajo es motivar el debate científico para beneficio de la sociedad.

\section{Antecedentes normativos del Artículo 157 del Código Tributario vigente}

En línea paralela al tratamiento normativo que ha tenido en el tiempo -a nivel constitucional y legal- el proceso contencioso-administrativo -en especial, el tema referido a la legitimidad para obrar activa-, es importante conocer que en materia tributaria desde el Primer Código Tributario (aprobado por Decreto Supremo 263-H), hasta el Código Tributario vigente siempre ha existido regulación sobre la materia. Es decir, más allá de las imprecisiones, omisiones o tratamiento antitécnico sobre la materia (por ejemplo, muchas veces producto del no reconocimiento a nivel legal del avance procesal sobre la materia), lo cierto es que el legislador nacional siempre estableció una regulación especial para la impugnación de una Resolución del Tribunal Fiscal (RTF).

Tratándose de una normativa especial, el tratamiento normativo previsto en el Primer Código Tributario ${ }^{(6)}$ al Código Tributario vigente $^{(7)}$, se entiende que siempre debió

(4) En esa línea se encuentra el artículo 36 de la Declaración Americana de los Derechos y Deberes del Hombre, el cual establece que "[t]oda persona tiene el deber de pagar los impuestos establecidos por la ley para el sostenimiento de los servicios públicos".

(5) Al respecto, véase Fernández (1995, p. 35 y pp. 41-42); García (2001, p. 267); Málvarez (2001, p. 407).

(6) Al respecto, véase la Norma X del Título Preliminar del Primer Código Tributario; y, la Norma IX del Título Preliminar del Segundo Código Tributario (aprobado por Decreto Ley 25859), y del Tercer Código Tributario (aprobada por Decreto Legislativo 773).

(7) Código Tributario.

Norma IX: Aplicación supletoria de los principios del Derecho: En lo no previsto por este Código o en otras normas tributarias podrán aplicarse normas distintas a las tributarias siempre que no se les opongan ni las desnaturalicen. Supletoriamente se aplicarán los Principios del Derecho Tributario, o en su defecto, los Principios del Derecho Administrativo y los Principios Generales del Derecho. 
y debe prevalecer sobre la regulación general que existió y existe sobre la materia ${ }^{(8)}$. Veamos a continuación el tratamiento normativo dispensado al artículo 157 del Código Tributario vigente. Esto nos permitirá advertir, a partir de una interpretación histórica, los alcances normativos del tratamiento actual relativo a la legitimidad para obrar activa por parte de la Administración Tributaria.

\subsection{Acerca del texto original previsto en el Decreto Legislativo 816}

Mediante Decreto Legislativo $816^{(9)}$ se aprobó el Código Tributario vigente. En concreto, para fines del presente documento, en el artículo 157 del Código Tributario, ubicado en el Título IV (Procesos ante el Poder Judicial) del Libro Tercero (Procedimientos Tributarios) se reguló la "demanda contencioso-administrativa".

Como cuestión previa, es importante notar que, a diferencia de lo previsto en el segundo ${ }^{(10)}$ y tercer ${ }^{(11)}$ Código Tributario, el artículo $124^{(12)}$ del Código Tributario vigente no consideró la demanda contencioso-administrativa como una de las etapas del procedimiento contencioso-tributario. Sin embargo, su regulación siguió incluida en el Título IV del Libro Tercero del Código Tributario, referida a los "procedimientos tributarios". Al respecto, conviene precisar que la impugnación de una RTF ante el Poder Judicial, vía la interposición de la correspondiente demanda contenciosa-administrativa, no tiene naturaleza de procedimiento administrativo (tributario). En estricto, nos encontramos ante un proceso, en específico, a un proceso de naturaleza judicial. En ese sentido, se aprecia y advierte que la denominación utilizada por el legislador en el texto original del artículo 157 del Código Tributario, referida a "Procedimiento ante el Poder Judicial", era antitécnica.

Un segundo aspecto a destacar, es que originariamente el Título IV del Libro Tercero fue denominado "demanda contenciosoadministrativa ante el Poder Judicial". A la fecha, empero, se ha modificado la denominación por "procesos ante el Poder Judicial". Aun cuando su denominación actual es más precisa, por tratarse su naturaleza de un proceso judicial, la misma sigue siendo defectuosa por referir a "procesos". En el Título IV del Libro Tercero, en estricto, solo se está regulando el proceso contenciosoadministrativo en materia tributaria. No se está regulando algún otro proceso judicial de distinta naturaleza.

Ahora bien, hechas las precisiones anteriores, a fin de entender el tratamiento normativo que establece el Código Tributario vigente sobre la legitimidad para obrar activa de la Administración Tributaria, es importante explicar sus modificaciones en el tiempo. Así se podrá entender, desde de un criterio interpretativo histórico, los alcances normativos de sus disposiciones legales.

(8) Al respecto de aplicar en forma supletoria normas distintas a las tributarias ante la falta de una regulación especial en esta materia y siempre y cuando no sea contraria o desnaturalice la ley tributaria, véase sentencias de casación emitidas por la Corte Suprema de Justicia en los expedientes No. 2483-2017, 2756-2017, 3610-2018, 3859-2017, 4076-2017, 5138-2017, 5148-2017, 6271-2017, 6542-2017, 6573-2017, 13417-2017, 14350-2017, 15924-2017, 17656-2016, 18194-2017, 26901-2017, 7678-2017, 13201-2016, 12246-2017, 7307-2017, 12361-2017, entre otras.

(9) Publicado en el Diario Oficial El Peruano el 21 de abril de 1996, entrando en vigencia a partir del día siguiente de su publicación Mediante Decreto Supremo 133-2013-EF, publicado en el Diario Oficial El Peruano el 22 de junio de 2013, se aprobó el Texto Único Ordenado vigente del Código Tributario.

(10) Decreto Ley 25859

Artículo 124: Son etapas del procedimiento contencioso:

a) Las reclamaciones antes la Administración Tributaria.

b) La apelación ante el Tribunal Fiscal.

c) La revisión ante el Poder Judicial.

(...).

(11) Decreto Legislativo 773

Artículo 124: Son etapas del procedimiento contencioso:

a) Las reclamaciones antes la Administración Tributaria.

b) La apelación ante el Tribunal Fiscal.

c) La revisión ante el Poder Judicial.

(...).

(12) Código Tributario.

Artículo 124: ETAPAS DEL PROCEDIMIENTO CONTENCIOSO-TRIBUTARIO

Son etapas del Procedimiento Contencioso-Tributario:

a) La reclamación ante la Administración Tributaria.

b) La apelación ante el Tribunal Fiscal.

(...). 
Así, el texto original del artículo 157 y siguientes del Código

Tributario establecieron expresamente lo siguiente:

\section{Artículo 157: DEMANDA CONTENCIOSO-ADMINISTRATIVA.}

Contra lo resuelto por el Tribunal Fiscal podrá interponerse demanda contencioso-administrativa, la misma que se regirá por las normas contenidas en el presente Título.

La demanda podrá ser presentada por la Administración Tributaria o por el deudor tributario ante el Tribunal Fiscal, dentro del término de quince (15) días hábiles computados a partir del día siguiente de efectuada la notificación certificada de la resolución al deudor tributario, debiendo tener peticiones concretas. Su presentación no interrumpe la ejecución de los actos o resoluciones de la Administración Tributaria (énfasis agregado).

El Tribunal Fiscal, en caso que el demandante cumpla con los requisitos de admisibilidad establecidos en el presente Título, elevará el expediente a la Sala competente de la Corte Suprema dentro de los quince (15) días hábiles siguientes a la fecha de la interposición de la demanda. De no cumplirse con los requisitos de admisibilidad señalados, el Tribunal Fiscal declarará inadmisible la demanda.

Artículo 158.- REQUISITOS DE ADMISIBILIDAD - DEUDOR TRIBUTARIO

Para la admisión de la demanda contencioso-administrativa presentada por el deudor tributario, será indispensable que acredite el pago de la deuda tributaria o presente carta fianza bancaria por el monto de la misma, además de la constancia de la fecha de notificación certificada de la resolución materia de impugnación.

Cuando se presente carta fianza bancaria, podrá solicitarse a la Administración Tributaria la suspensión de la cobranza por el plazo de la misma, debiendo renovarse la carta fianza bancaria cada seis (6) meses hasta por el monto de la deuda tributaria, debidamente actualizada a la fecha de la renovación.

Artículo 159: DEFENSA DE LA ADMINISTRACION TRIBUTARIA:

La Administración Tributaria a través de los representantes designados por la misma, defenderá los intereses relacionados con los tributos que administra.

Artículo 160: INFORME ORAL Y ALEGATOS:

Los interesados podrán solicitar el uso de la palabra y presentar su alegato escrito dentro de los diez (10) días hábiles siguientes a la fecha de recepción del recurso por la Sala competente de la Corte Suprema.
Quién represente los intereses del acreedor tributario podrá hacerlo dentro del mismo término, computado desde que se le notificó la presentación de la demanda contenciosoadministrativa.

Artículo 161: PLAZO PARA RESOLVER:

La Sala competente de la Corte Suprema expedirá resolución en el término de sesenta (60) días hábiles, computados desde el vencimiento del término previsto en el artículo anterior" (énfasis agregado).

A partir de la regulación prevista en el artículo 157 y siguientes del Código Tributario vigente, se advierte lo siguiente:

(i) Era posible interponer demanda contenciosa-administrativa con motivo de lo resuelto por el TF, conforme a las normas del Título IV del Código Tributario.

Esta disposición no estableció, originalmente y en forma expresa, la aplicación supletoria de algún cuerpo normativo procesal. Fue necesario en su oportunidad (13) establecer la remisión expresa al Código Procesal Civil, vigente en ese momento ${ }^{(14)}$, para regularizar la operatividad de la impugnación de una RTF en la vía judicial. Nótese, empero, a modo referencial, que esta aplicación supletoria del Código Procesal Civil suponía aplicar las reglas de este proceso a la impugnación de una RTF, las mismas que son de naturaleza distinta para el fin del proceso contencioso administrativo (Priori, 2002, p. 63), en especial tratándose de casos en los que se involucra materia tributaria (por ejemplo., principios aplicables al proceso civil frente al proceso contencioso administrativo, como podría ser el caso del principio de verdad material) (Dromi, 1999, p. 128).

(ii) Era necesario, conforme a lo previsto en el Código Procesal Civil( ${ }^{(15)}$, que la RTF haya

(13) Mediante la Ley 27038, publicada en el Diario Oficial El Peruano el 31 de diciembre de 1998, entrando en vigencia al día siguiente de su publicación, se modificó diversas disposiciones del Código Tributario. En concreto, mediante la Cuarta Disposición Final de la Ley 27038 , se precisó que "(...) la demanda contencioso-administrativa contra lo resuelto por el Tribunal Fiscal, es tramitada conforme a lo establecido en el Código Tributario y en lo no previsto en éste, es de aplicación supletoria lo establecido en el Código Procesal Civil". Asimismo, mediante la Quinta Disposición Final de la Ley 27038, se incorporó un último párrafo del artículo 542 del Código Procesal Civil, mediante el cual se dispuso que "[t]ratándose de la impugnación de resoluciones emanadas del Tribunal Fiscal, se aplicará el procedimiento establecido en el Código Tributario".

(14) El 2 de agosto de 1993 entró en vigencia el Código Procesal Civil. Conforme a lo previsto en el numeral 6 del artículo 486 este cuerpo legal, la impugnación de una resolución administrativa se seguía en la vía del proceso abreviado.

(15) El numeral 1 y 2 del artículo 541 del Código Procesal Civil establecían que constituyen requisitos de admisibilidad de la demanda, que la impugnación "[s]e refiera a un acto o resolución que cause estado" y que "[e]l acto o la resolución se hayan impugnado en la vía administrativa, agotando los recursos previstos en las leyes respectivas". En estricto, empero, se tratan de requisitos de procedencia de la demanda. 
causado estado(16) y que se hayan agotado los recursos previstos en las leyes respectivas.

Como regla general, esto supone que se haya interpuesto el correspondiente: (i) recurso de reclamación, ante la Administración Tributaria (generando la emisión de la Resolución de Intendencia que resuelve el caso); y, (ii) recurso de apelación, ante la Administración Tributaria, el cual es elevado al Tribunal Fiscal (generando la emisión de la RTF del caso). Asimismo, es esta RTF, la que debe establecer un criterio o pronunciamiento en la vía administrativa que afecte la situación jurídica del titular del derecho material (en forma definitiva en caso no sea cuestionado), la que podrá ser impugnada en la vía judicial correspondiente $^{(17)}$.

(iii) La legitimidad para obrar activa para interponer la demanda contenciosa administrativa fue prevista para la Administración Tributaria y el deudor tributario.

Esta referencia expresa es importante, por ejemplo, porque en el artículo 138 del Primer Código Tributario ${ }^{(18)}$ solo se hacía referencia a los "interesados que no se conformen con las resoluciones del Tribunal Fiscal, podrán impugnarlas interponiendo demanda judicial (...)". Es decir, el legislador cuidó de establecer una habilitación específica y expresa para que la Administración Tributaria pueda impugnar una RTF en la vía judicial.

(iv) Aun cuando se establecía que la Administración Tributaria podía impugnar una RTF en la vía judicial, se advierte que la legitimidad para obrar activa de esta entidad no era naturaleza ordinaria.

Según su más difundida noción, se entiende que la legitimidad para obrar es la aptitud para ser parte en un proceso en concreto (Gonzáles, 2001, p. 174). Existen diversas clasificaciones sobre la legitimidad para obrar en función a diversos factores. Para efectos del presente trabajo, se entiende que la legitimidad para obrar activa es de naturaleza ordinaria, cuando se debe reconocer en la relación procesal a quien afirma ser titular de la relación material involucrada (Monroy, 2004, p. 232). Por su parte, es de naturaleza extraordinaria, cuando se establece por mandato de la ley la posibilidad que determinada persona o entidad inicie un proceso judicial, aun cuando no sean titulares de la relación material involucrada ${ }^{(19)}$

En nuestra legislación tributaria, es importante conocer que: (i) el acreedor tributario es el titular en favor del cual se cumple la prestación tributaria ${ }^{(20)}$; y, (ii) la Superintendencia Nacional de Aduanas y de Administración Tributaria (SUNAT), como su propia denominación lo indica, es una entidad administradora de los tributos internos y arancelarios ${ }^{(21)}$. En ese sentido, la Administración Tributaria -en tanto no es el acreedor tributario-, no es titular de la relación material involucrada. Por tanto, consideramos que la Administración Tributaria no tenía propia y técnicamente legitimidad para obrar activa ordinaria. Ante ello, se ha señalado que:

(16) Sobre el agotamiento de la vía administrativa tributaria, ha existido y existe mucha discusión hasta la fecha en la vía judicial sobre el tema. En muchos casos, por: (i) el alcance de la noción "causar estado"; y, (ii) la técnica resolutiva empleada por la emisión de las resoluciones del Tribunal Fiscal (por ejemplo, resoluciones que disponen, "revocar, debiendo la Administración Tributaria proceder conforme a lo indicado en la presente resolución"). Esto generó y ha generado mucha litigiosidad por la declaración de improcedencia de las demandas contencioso-administrativas interpuestas, tanto por los deudores tributarios como por la propia Administración Tributaria. En el tiempo, las Salas Especializadas en lo Contencioso Administrativo Tributario y la propia Corte Suprema de Justicia se han encargado de fijar criterios sobre la materia. En tal sentido, véase sentencias de casación emitidas por la Corte Suprema de Justicia en los expedientes 6733-2013-LIMA, 366-2016-LIMA, 3605-2008-LIMA, entre otras.

(17) En relación a la exigencia de "causar estado", véase Danós, J. (2000). El proceso contencioso administrativo en materia tributaria. Themis. Revista de Derecho, 41, pp. 87 y ss.

(18) Artículo 138:

Los interesados que no se conformen con las resoluciones del Tribunal Fiscal, podrán impugnarlas interponiendo demanda judicial, de conformidad con lo dispuesto en los artículos 11 y 184 de la Ley Orgánica del Poder Judicial.

(19) Por legitimidad para obrar activa extraordinaria, nos encontramos en el supuesto referido a la "(...) permisión legal expresa a determinados personas a iniciar un proceso, a pesar de no ser titulares de las situaciones jurídicas subjetivas que se llevan a él (...)" (Priori, 2002, p. 176).

(20) Artículo 4: ACREEDOR TRIBUTARIO:

Acreedor tributario es aquél en favor del cual debe realizarse la prestación tributaria.

El Gobierno Central, los Gobiernos Regionales y los Gobiernos Locales, son acreedores de la obligación tributaria, así como las entidades de derecho público con personería jurídica propia, cuando la ley les asigne esa calidad expresamente.

(21) Artículo 50: COMPETENCIA DE LA SUNAT:

La SUNAT es competente para la administración de tributos internos y de los derechos arancelarios, así como para la realización de las actuaciones y procedimientos que corresponda llevar a cabo a efecto de prestar y solicitar la asistencia administrativa mutua en materia tributaria. 
(...) el titular de la situación jurídica sustancial tiene legitimidad para obrar activa (Ley 27584, art. 11), lo cual, a nuestro modo de ver, implica que solo el contribuyente o responsable tiene potestad para iniciar la demanda contenciosa administrativa, más no así el órgano administrador del tributo, porque éste no es titular de la situación jurídica sustantiva sino el acreedor tributario (Robles et al., 2009, p. 589).

Su legitimidad para obrar activa, prevista en el artículo 157 del Código Tributario, entonces, se debía entender de naturaleza extraordinaria. Es decir, sujeta a los alcances de la autorización legal expresa prevista para tal efecto. En esa línea se encontraba lo previsto. Primero, el artículo 159 del Código Tributario, el cual disponía que la Administración Tributaria "(...) defenderá los intereses relacionados con los tributos que administra"; y, segundo, el artículo 160 del Código Tributario, el cual disponía que "quien represente los intereses el acreedor tributario" podrá solicitar el uso de la palabra y presentar alegatos. Ambas disposiciones, como se aprecia, resaltaban la naturaleza de ente administrador de la Administración Tributaria.

(v) La impugnación de una RTF en la vía judicial era una de mero control de legalidad

En atención a que la legitimidad para obrar activa de la Administración Tributaria, como se ha explicado en el punto previo, era de naturaleza extraordinaria, la posibilidad de impugnar una RTF estaba sujeto a lo previsto específica y expresamente en la ley de autorización.

Esta premisa es de la mayor relevancia, porque supone que solo y únicamente en los supuestos de habilitación legal es posible que la Administración Tributaria pueda impugnar válidamente una RTF en la vía judicial correspondiente. En concreto, toda vez que se trata de supuestos de excepción a la regla general (esto es, se parte de la premisa de que la Administración Tributaria no tiene legitimidad para obrar activa ordinaria), es correcto señalar que los mismos deben interpretarse en forma restrictiva, no pudiendo extenderse o crearse supuestos no previstos por ley ${ }^{(22)}$. Frente a una posible duda sobre la interpretación de los alcances de la ley habilitante de la legitimidad para obrar activa extraordinaria de la Administración Tributaria, la conclusión debería ser que el supuesto no está regulado o, de ser el caso, que excede los alcances del mismo.

Establecido lo anterior, es importante notar que en el texto original del artículo 157 del Código Tributario, no se estableció expresamente -entre otros aspectos-, en forma directa y específica las causales concretas por las cuales era posible legalmente que la Administración Tributaria pueda impugnar una RTF. En ese sentido, como también se ha explicado, era de aplicación supletoria el artículo 540(23) del Código Procesal Civil. Esta disposición establecía que la impugnación del acto o resolución administrativa estaba prevista para que se declare su invalidez o ineficacia.

Sobre esa base de ideas, se podía concluir válidamente que, en el supuesto previsto para la legitimidad para obrar activa de la Administración Tributaria, la misma que tenía naturaleza extraordinaria (ejemplo, solo por ley, en forma excepcional y restringida), la pretensión que se podía formular en las correspondientes demandas contenciosas administrativas era de naturaleza meramente nulificante (control de legalidad) ${ }^{(24)}$. No era posible formular y obtener pronunciamientos de plena jurisdicción, como podría haberse alegado partiendo de una interpretación para un supuesto de legitimidad para obrar activa

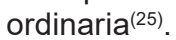

(vi) La demanda contenciosa administrativa debía contener peticiones concretas

(22) Adviértase que el Artículo IV del Título Preliminar del Código Civil establece que "[l]a ley que establece excepciones o restringe derechos no se aplica por analogía" (el subrayado es agregado nuestro). En el mismo sentido se encuentra el (actual) segundo párrafo de la Norma VIII del Título Preliminar del Código Tributario, el cual dispone que "[e]n vía de interpretación no podrá crearse tributos, establecerse sanciones, concederse exoneraciones, ni extenderse las disposiciones tributarias a personas o supuestos distintos de los señalados en la ley".

(23) Artículo 540: Procedencia:

La demanda contencioso administrativa se interpone contra acto o resolución de la administración a fin que se declare su invalidez o ineficacia

(24) Se ha señalado que la pretensión de control de legalidad “(...) solamente otorgaba un carácter puramente declarativo a las sentencias estimatorias; y que además, no contempla la posibilidad de extraer de la anulación declarada las consecuencias que realmente interesan al recurrente que ha ganado el proceso (...)" [Espinosa-Saldaña, E. (2003). El nuevo proceso contencioso administrativo peruano: ¿Principio del fin de nuestro amparo alternativo?. Jurisdicción constitucional, Impartición de Justicia y Debido Proceso (p. 257). Ara Editores].

(25) Al respecto, véase Espinosa-Saldaña, E. (2003). El nuevo proceso contencioso administrativo peruano: ¿Principio del fin de nuestro amparo alternativo?. Jurisdicción constitucional, Impartición de Justicia y Debido Proceso (pp. 244-245). Ara Editores. 
La exigencia de formular peticiones concretas se entiende que constituye un presupuesto procesal, específicamente un requisito formal de la demanda, que responde a la necesidad que el órgano resolutor y el demandado tengan claridad, entre otros aspectos, sobre: ¿qué se demanda?, ¿por qué se demanda? ${ }^{(26)}$. Esto, en atención a que la oscuridad o ambigüedad en la forma de proponer las pretensiones en la demanda, genera, básicamente, un doble efecto: (i) por un lado, no permite tener claridad sobre los alcances de lo pretendido por el demandante, generación afectación al derecho de contradicción efectiva del demandado; y, (ii) por otro lado, no permite al juez tener claridad sobre las pretensiones y alcance de las mismas sobre las que debe emitir pronunciamiento jurisdiccional.

(vii) No era posible la impugnación de la RTF que haya establecido jurisprudencia de observancia obligatoria

Conforme a lo previsto en el último párrafo del artículo 154 del Código Tributario, modificado por la Ley $27308^{(27)}$, la Administración Tributaria no podía interponer demanda contenciosa administrativa en los casos que el Tribunal Fiscal haya emitido una resolución que establezca jurisprudencia de observancia obligatoria ${ }^{(28)}$. Esta prohibición legal expresa se encuentra vigente hasta el día de hoy en el artículo 154 del Código Tributario.

(viii) El plazo para demandar, al igual que lo previsto en su momento en el Segundo y Tercer Código Tributario, es de quince (15) días hábiles siguientes a la notificación de la RTF al deudor tributario(29).

Esto, probablemente, partiendo del entendimiento del legislador que la impugnación de una RTF ante el Poder Judicial era un procedimiento administrativo tributario adicional a seguir. (ix) La interposición de la demanda contenciosa administrativa no interrumpe la ejecución de los actos o resoluciones de la Administración Tributaria.

Es decir, se reconoce la vigencia del principio de ejecutoriedad del acto administrativo, en este caso, de naturaleza tributaria. Su no ejecución, por tanto, solo era posible -como regla general-, mediante la obtención de la correspondiente medida cautelar.

(x) La demanda contenciosa-administrativa tributaria se presenta ante el propio Tribunal Fiscal, quien deberá elevar el expediente ante la Corte Suprema ${ }^{(30)}$, previo cumplimiento de los requisitos correspondientes.

La disposición en mención establecía a nivel artículo 157 del Código Tributario la competencia funcional de primera instancia para conocer los procesos contenciosos administrativos. Sin embargo, como fue corregido en el tiempo, este tema debería ser dejado en forma directa a la regulación procesal, para facilitar la operatividad y funcionalidad de los procesos judiciales.

(xi) Para la admisión a trámite de la demanda, uno de los supuestos previstos era el pago de la deuda tributaria.

A diferencia de lo que ocurría con el Primer Código Tributario $^{(31)}$, en el que se

(26) Sobre los requisitos formales de la demanda, véase Monroy, J. (2017) Temas de Derecho Procesal (Tomo 2) (pp. 49-50). Communitas.

(27) Artículo 154: JURISPRUDENCIA DE OBSERVANCIA OBLIGATORIA:

(...) En los casos de resoluciones que establezcan jurisprudencia obligatoria, la Administración Tributaria no podrá interponer demanda contencioso-administrativa.

(28) El primer párrafo del texto original del artículo 154 del Código Tributario establecía que constituía resolución de observancia obligatoria las resoluciones del Tribunal Fiscal que interpreten de modo expreso y con carácter general el sentido de las normas tributarias. En el tiempo, producto de las modificaciones producidas por la Ley 27308, por el Decreto Legislativo 1113 y por la Ley 30264 , el primer párrafo del artículo 154 del Código Tributario establece al día de hoy que constituyen resoluciones de observancia obligatoria: (i) resoluciones del Tribunal Fiscal que interpreten de modo expreso y con carácter general el sentido de las normas tributarias; (ii) las emitidas en virtud del Artículo 102 del Código Tributario (por ejemplo, aplicación de la norma de mayor jerarquía); (iii) las emitidas en virtud a un criterio recurrente de las Salas Especializadas; y, (iv) las emitidas por los Resolutores - Secretarios de Atención de Quejas por asuntos materia de su competencia.

(29) El segundo párrafo del artículo 138 del Código Tributario establecía que "[e]l término para interponer esta demanda será de seis meses contados desde la fecha de la notificación de la resolución del Tribunal Fiscal".

(30) El segundo párrafo del artículo 542 del Código Procesal Civil, establecía que "[c]uando la impugnación se refiere a Resolución Suprema, o resoluciones emanadas de las asambleas regionales, del Banco Central de Reserva, de la Superintendencia de Banca y Seguros, de la Contraloría General de la República, del Tribunal Fiscal, Tribunal de Aduanas o de los órganos de gestión de la Corte Suprema, es competente en primera instancia la Sala especializada de la Corte Suprema".

(31) Artículo 139: Para la admisión de la demanda será requisito indispensable la presentación del comprobante de pago del tributo y la constancia de la fecha de la notificación de la resolución del Tribunal Fiscal materia de la impugnación. 
establecía como requisito únicamente el pago del tributo, en el texto en comentario se establece que corresponde el pago de la deuda tributaria (por ejemplo, tributo, multa y los intereses correspondientes). No obstante lo anterior, se advierte que se presentaba la aplicación del principio del solve et repete ${ }^{(32)(33)}$, situación proscrita en nuestro ordenamiento jurídico(34).

Como se puede apreciar de la regulación prevista en el texto original de los artículos 157 al 161 del Código Tributario, la Administración Tributaria -en tanto no es el acreedor tributario-, no tenía legitimidad para obrar activa ordinaria. Su legitimidad para obrar activa, se debía entender de naturaleza extraordinaria. Asimismo, considerando que era de aplicación supletoria el Código Procesal Civil, se entendía que las pretensiones que se podían formular en las correspondientes demandas contenciosas administrativas eran de naturaleza meramente declarativas de nulidad (control de legalidad), no siendo posible obtener pronunciamientos de plena jurisdicción.

\subsection{Acerca de la derogación prevista por la Primera Disposición Derogatoria de la LPCA}

El texto original de los artículos 157 al 161 del Código Tributario estuvieron vigentes entre el 22 de abril de 1996 hasta el 16 de abril de 2002. Esto se debe a que estas disposiciones fueron derogadas por el numeral 3 de la Primera Disposición Derogatoria de la Ley del Proceso Contencioso Administrativo, aprobada por Ley 27584, cuyo Texto Único Ordenado vigente fue aprobado por Decreto Supremo 011-2019-JUS (en adelante, "LPCA"), cuerpo legal que entró en vigencia el 15 de abril de $2002^{(35)(36)}$.
En ese sentido, entre el 17 de abril de 2002 y el 5 de febrero de 2004 (por ejemplo, aproximadamente, 2 años, producto de la entrada en vigencia del Decreto Legislativo 953, según se explica en el punto siguiente), la impugnación de una RTF se encontró regulada en forma directa -y no supletoria- por lo previsto en la LPCA.

La entrada en vigencia de la LPCA, con la consecuente derogación normativa de la materia prevista en el Código Tributario, fue y es de la mayor relevancia en nuestra legislación procesal, porque supuso un cambio en la concepción del proceso contencioso administrativo.

Así, se pasaba formalmente de un proceso contencioso administrativo de mero control de legalidad de las actuaciones administrativas (esto es, por ejemplo, una RTF), como así se entendió el proceso seguido conforme a las normas previstas en su momento en el Código Procesal Civil, a uno que permite dar tutela efectiva a los demandantes, a través del pronunciamiento sobre las pretensiones de plena jurisdicción (Espinosa-Saldaña, 2003, p. 254); (Priori, 2002, p. 65).

Ahora bien, para establecer los alcances de la legitimidad para obrar activa de la Administración Tributaria, es importante

(32) En relación a una legislación similar, mediante sentencia emitida en el expediente No. 3548-2003-AA/TC, el TC estableció que “(...) atendiendo a que la demanda contencioso-administrativa fue declarada inadmisible, tras no haberse satisfecho los requisitos que contempla el artículo $158^{\circ}$ del Código Tributario, el Tribunal Constitucional considera que se ha acreditado la lesión del derecho de acceso de justicia" (Tribunal Constitucional, 2004, F.J. 7). A este efecto, el literal b) del artículo 158 del Código Tributario vigente, antes de la modificación realizada por el Decreto Legislativo 953, establecía que [p]ara la admisión de la demanda contenciosoadministrativa, será indispensable:

(...) b) Acreditar el pago de la deuda tributaria actualizada a la fecha de la interposición de la demanda contencioso-administrativa o presentar carta fianza bancaria o financiera por el monto de la deuda actualizada hasta por seis meses posteriores a la fecha de interposición de la demanda. La referida carta fianza debe otorgarse por un periodo de seis meses, renovarse por periodos similares dentro del plazo que señale la administración y hasta por el monto de la deuda tributaria, debidamente actualizada a la fecha de la renovación.

(33) El artículo 158 del Código Tributario, modificado por el Decreto Legislativo 953, eliminó la exigencia prevista en el literal b) original. Sobre esa base, por ejemplo, se consideró que la normativa tributaria no establecía la aplicación del principio del solve et repete para la interposición de demandas en la vía judicial. Al respecto, véase sentencia del Tribunal Constitucional recaída en el Expediente No. 3252-2005-PA/TC.

(34) En tal sentido, véase sentencia del Tribunal Constitucional recaída en el Expediente No. 3741-2004-AA/TC, y su aclaración emitida en la sentencia del Expediente No. 4242-2006-PA/TC; así como Giuliani, C. (2003). Derecho Financiero (9. ${ }^{a}$ ed., vol. II) (p. 682). Editorial La Ley.

(35) LA LPCA fue publicada en el Diario Oficial El Peruano el 7 de diciembre de 2001. Sin embargo, mediante la Tercera Disposición Final de la LPCA, se dispuso que su entrada en vigencia fuera efectiva a los 30 días naturales siguientes a su publicación. Mediante Decreto de Urgencia 136-2001, publicado en el Diario Oficial El Peruano el 21 de diciembre de 2001, se difirió en 180 días el plazo de entrada en vigencia de la LPCA. Por Ley 27684, publicada en el Diario Oficial el 16 de marzo de 2002, se derogó el Decreto de Urgencia 136-2001, disponiendo la entrada en vigencia de la LPCA a los 30 días posteriores de la publicación de su publicación.

(36) Similar situación ocurrió con los artículos 540 al 545 del Código Procesal Civil, disposiciones que fueron derogadas por el numeral 1 de la Primera Disposición Derogatoria de la LPCA. 
advertir que el artículo 11 (ahora 13) de la LPCA ${ }^{(37)}$ establecía que la misma le correspondía: (i) al titular de la situación jurídica sustancial (primer párrafo); y, (ii) también a las entidades públicas, siempre que hayan sido autorizadas por ley, sujeto al cumplimiento de ciertos requisitos (segundo párrafo). Conforme a esta disposición, en nuestra opinión, la Administración Tributaria no contaba con la legitimidad para obrar activa prevista en el primero párrafo del artículo 11 (ahora 13) de la LPCA, toda vez que esta solo estaba autorizada para el "titular de la situación jurídica sustancial".

Este no es el caso de la Administración Tributaria, como se ha explicado en líneas previas, porque: (i) es el acreedor tributario el titular en favor del cual se cumple la prestación tributaria; y, (ii) la SUNAT solo es la entidad administradora de los tributos internos y arancelarios.

En relación al supuesto previsto en el segundo párrafo del artículo 11 (ahora 13 de la LPCA), se entiende que éste está referido al proceso contencioso especial de lesividad (Espinosa-Saldaña, 2003, p. 254); (Priori, 2002, p. 168); (Morón, 2015, pp. 226-227); (Huapaya, 2006, pp. 890-891). Es decir, nos encontramos ante el supuesto de un proceso judicial en el que la entidad pública que pretende la nulidad de un acto administrativo ha sido la misma autora de la emisión de dicho acto. En ese sentido, se ha señalado que

(...) muchos entienden que bajo el proceso de agravio se deben canalizar todas las demandas contencioso-administrativas que sean formuladas por la Administración Pública. En ese sentido, es preciso puntualizar, que dicha afirmación es falsa y carente de todo fundamento, toda vez que la legitimación activa prevista en la norma antes referida, se reduce única y exclusivamente a los supuestos en los cuales una entidad pública pretende demandar la nulidad de un acto propio (expreso o presunto) por vencimiento de los plazos previstos para la declaración administrativa de nulidad de oficio previstos en el artículo $202^{\circ}$ de la LPAG. Es decir, no hay que confundir el proceso de agravio, con toda situación en la cual la Administración Pública aparezca como demandante en un proceso contencioso-administrativo (Huapaya, 2010, p. 96).

Para ello, según el texto en mención, se debe acreditar: (i) cuál es el agravio a la legalidad administrativa y al interés público (esto es, no basta la afectación a la mera legalidad) (Morón, 2015 p. 232); y, (ii) que haya vencido el plazo para que la entidad administrativa pueda haber declarado nulo de oficio el acto administrativo impugnado.
Este no es el supuesto que se presenta cuando la Administración Tributaria impugna una RTF (acto administrativo emitido por el Tribunal Fiscal, entidad distinta de la autoridad tributaria), en la vía del proceso contencioso administrativo. Por tanto, en el período vigente entre el 17 de abril de 2002 y el 5 de febrero de 2004, la Administración Tributaria no podía alegar válidamente la aplicación del primer o segundo párrafo del artículo 11 (ahora 13) de la LPCA, para impugnar una RTF en la vía judicial.

\subsection{Acerca de la modificación prevista por el Decreto Legislativo 953}

El 5 de febrero de 2004, fue publicado en el Diario Oficial El Peruano el Decreto Legislativo $953^{(38)}$, mediante el cual se realizaron diversas modificaciones al Código Tributario.

En concreto, mediante el artículo 76 del Decreto Legislativo 953, se incorporó nuevamente el artículo 157 del Código Tributario, en los siguientes términos:

\section{Artículo 157: DEMANDA CONTENCIOSO} ADMINISTRATIVA:

La resolución del Tribunal Fiscal agota la vía administrativa. Dicha resolución podrá impugnarse mediante el Proceso Contencioso Administrativo el cual se regirá por las normas contenidas en el presente Código y supletoriamente por la Ley $\mathrm{N}^{\circ} 27584$ - Ley que regula el Proceso Contencioso Administrativo.

La demanda podrá ser presentada por la Administración Tributaria, previa autorización del Ministro de Economía y Finanzas tratándose de SUNAT, o por el deudor tributario ante la Sala Contencioso Administrativa de la Corte Superior respectiva, dentro del término de tres (3) meses computados, para cada uno de los sujetos antes mencionados a partir del día siguiente de efectuada la notificación de la resolución debiendo tener peticiones concretas.

La presentación de la demanda no interrumpe la ejecución de los actos o resoluciones de la Administración Tributaria" [énfasis agregado].

(37) Artículo 13.- Legitimidad para obrar activa

Tiene legitimidad para obrar activa quien afirme ser titular de la situación jurídica sustancial protegida que haya sido o esté siendo vulnerada por la actuación administrativa impugnable materia del proceso.

También tiene legitimidad para obrar activa la entidad pública facultada por ley para impugnar cualquier actuación administrativa que declare derechos subjetivos; previa expedición de resolución motivada en la que se identifique el agravio que aquella produce a la legalidad administrativa y al interés público, y siempre que haya vencido el plazo para que la entidad que expidió el acto declare su nulidad de oficio en sede administrativa.

(38) Conforme al artículo 101 del Decreto Legislativo 953, este cuerpo legal entró en vigencia al día siguiente de su publicación en el Diario Oficial El Peruano, esto es, el 6 de febrero de 2004 
Según se puede advertir, el tratamiento previsto en el artículo 157 y demás pertinentes del Código Tributario, vigente a esa fecha, para la impugnación de una RTF, partía por considerar que: (i) la RTF agota la vía administrativa tributaria ${ }^{(39)}$; (ii) la RTF se podía impugnar en un proceso contencioso-administrativo, conforme a lo previsto en el Código Tributario y, en forma supletoria, por las leyes vigentes de la LPCA; (iii) la Administración Tributaria podía impugnar una RTF, previa autorización del Ministerio de Economía y Finanzas (MEF); (iv) existía un plazo de tres (3) meses para interponer la demanda, contados a partir del día siguiente de realizada la notificación de la RTF; (v) la demanda contenciosoadministrativa tributaria debía tener peticiones concretas; (vi) la Administración Tributaria no podía impugnar judicialmente una RTF que haya establecido jurisprudencia de observancia obligatoria; (vii) la competencia funcional le correspondía a la Sala Contenciosa Administrativa de la Corte Superior respectiva; y, (viii) la interposición de la demanda contencioso administrativa-tributaria no interrumpía la ejecución de los actos o resoluciones de la Administración Tributaria.

Especial relevancia, para efectos del presente trabajo, es entender la racionalidad de la sujeción legal expresa de la Administración Tributaria a la autorización previa del MEF para la interposición de una demanda contenciosa-administrativa tributaria, conforme a lo previsto en el segundo párrafo del artículo 157 del Código Tributario, según modificación prevista por el Decreto Legislativo 953.

Al respecto, ya hemos señalado en líneas previas que en nuestra legislación tributaria: (i) el acreedor tributario es el titular en favor del cual se cumple la prestación tributaria; y, (ii) la SUNAT, como su propia denominación lo indica, es una entidad administradora de los tributos internos y arancelarios. En ese sentido, en atención a que: (i) la SUNAT es una entidad que se encuentra adscrita al MEF; y, (ii) el Tribunal Fiscal es un órgano resolutivo del MEF, el cual resuelve en última instancia las controversias entre la autoridad tributaria y los deudores tributarios; entonces, (iii) sería el MEF, como órgano superior jerárquico e integrante del Gobierno Central, quien tendría legitimidad para obrar activa ordinaria (Robles et al., 2009, p. 789). Es decir, la Administración Tributaria -en tanto no es el acreedor tributario-, no tenía propia y técnicamente legitimidad para obrar activa ordinaria. Su legitimidad para obrar activa, prevista en el artículo 157 del Código Tributario, modificado por el Decreto Legislativo 953, se debía seguir considerando de naturaleza extraordinaria.

Precisamente, en línea de lo señalado en el punto 3 anterior, el 4 de marzo de 2004 fue publicado en el Diario Oficial El Peruano el Decreto Supremo 035-2004-EF. Mediante esta disposición, se establecieron criterios para que el MEF pueda autorizar a la SUNAT a impugnar resoluciones del Tribunal Fiscal en la vía del proceso contencioso-administrativo tributario. En concreto, mediante el Decreto Supremo 035-2004-EF se estableció que la autoridad tributaria podrá interponer demanda contenciosa-administrativa con motivo de la notificación de una RTF, siempre que, en primer lugar, la solicitud de autorización previa al MEF deberá ser presentada en un plazo no mayor de cuarenta y cinco (45) días calendario contados desde la notificación de la RTF; en segundo lugar, a la solicitud se le deberá adjuntar un informe legal de sustento emitido por la Intendencia Nacional Jurídica de la SUNAT; en tercer lugar, la solicitud genere un informe favorable de la Defensoría del Contribuyente y del Usuario Aduanero del MEF; en cuarto lugar, la pretensión de la demanda contenciosa-administrativa se encuentra sustentada en los supuestos previstos en su artículo 3. Es necesario resaltar que la impugnación de una RTF en el proceso contencioso-administrativo tributario solo se podía producir en los tres (3) supuestos previstos en el artículo 3 del Decreto Supremo 035-2004-EF.

Más allá del cuestionamiento que podía haber existido en relación al cumplimiento del principio de reserva de ley, su interpretación, por la naturaleza de la actuación de la legitimidad para obrar activa de la Administración Tributaria, por tanto, debía ser interpretada en forma restrictiva y excepcional. Los supuestos previstos en los numerales 1 al 3 del artículo 3 del Decreto Supremo 035-2004-EF, que podían ser alegados y justificados por la Administración Tributaria, previa autorización del MEF, como supuestos habilitantes para interponer una demanda contenciosa-administrativa tributaria, fueron los siguientes:

(i) Existe un error de forma o de fondo en la RTF, el cual no pueda impugnarse por una vía procesal establecida en las normas vigentes.

(39) Nótese que el tema referido al agotamiento de la vía administrativa y si lo resuelto ha causado estado, existen diversos aspectos en discusión. Uno de ellos, es la posibilidad que se pueda impugnar en la vía del proceso contencioso administrativo una RTF emitida en un procedimiento de queja. Sobre este tema, existe diversa jurisprudencia de la Corte Suprema. Al respecto, por ejemplo, véase la Sentencia de Casación No. 4843-2012-LIMA, publicada en el Diario Oficial El Peruano el 9 de noviembre de 2020. 
El supuesto previsto en el numeral 1 del artículo 3 del Decreto Supremo 035-2004-EF, tiene dos (2) premisas para habilitar a la Administración Tributaria, previa autorización del MEF, para impugnar una RTF en la vía del proceso contencioso administrativo: (i) que la RTF haya incurrido en un error de forma o de fondo; y, (ii) que ese error de forma o de fondo no pueda ser corregido por otra vía procesal, distinta al proceso contencioso administrativo.

En relación a la primera premisa, se advierte que se trata de un supuesto en el que la Administración Tributaria tiene una apreciación distinta ("error") del criterio interpretativo establecido por el Tribunal Fiscal en una RTF. Esta situación, empero, no responde a la naturaleza del proceso contencioso administrativo, incluso en su vertiente de mero control de legalidad. Más aún, una interpretación en ese sentido no es acorde con una legitimidad para obrar activa extraordinaria, la cual está sujeta a la previsión de causales específicas y taxativas. Esto se hace más evidente, tratándose de errores de forma, los cuales podrían ser corregidos con la correspondiente solicitud de corrección, conforme a lo previsto en el artículo 153 del Código Tributario(40). Por tanto, una demanda con una pretensión basada en este supuesto debía ser declarada -técnicamente- improcedente.

En relación a la segunda premisa, nótese que era necesario que este error (de forma o fondo), no podía ser corregido mediante otra vía procesal prevista en la normativa durante su vigencia. Entendemos que se trataría, por tratarse de un supuesto de impugnación, por ejemplo, del proceso de lesividad. Siendo ello así, si era posible formalmente "corregir" el error de forma o fondo por una vía procesal, se tenía que seguir la misma, no siendo posible entonces que la autoridad tributaria pueda interponer válidamente una demanda contenciosa-administrativa.

(ii) Se trata de un tema distinto a la mera interpretación de las normas, de procedimientos o de pruebas sobre las cuales SUNAT en la etapa de la reclamación tuvo una opinión distinta al Tribunal Fiscal.

El supuesto previsto en el numeral 2 del artículo 3 del Decreto Supremo 035-2004-EF, tiene dos (2) premisas para habilitar a la Administración Tributaria, previa autorización del MEF, para impugnar una RTF en la vía del proceso contencioso administrativo: primero, que la pretensión impugnatoria de la RTF no debe estar sustentada en un tema de mera interpretación de las normas, de los procedimientos o de las pruebas; y, segundo, en estricto, siguiendo el orden de lo que ocurre en un procedimiento contencioso administrativo tributario, que el Tribunal Fiscal haya tenido una apreciación distinta de la posición de la SUNAT en etapa de reclamación sobre la interpretación.

En relación a la primera premisa, en nuestra opinión, esta causal debe ser interpretada como parámetro de habilitación general para impugnar una RTF en la vía del proceso contencioso administrativo. Es decir, nos encontramos ante una causal de exclusión, esto es, se regula que aspectos no pueden ser materia de impugnación de una RTF: solo si nos encontramos ante temas distintos a la interpretación de normas, procedimientos o pruebas, será posible demandar. Su ámbito de exclusión es amplio. Precisamente por ello, esta causal debía servir, a su vez, de parámetro de interpretación de las otras dos (2) causales previstas por el Decreto Supremo 035 2004-EF. Una interpretación distinta no sería posible, porque supondría un tratamiento contradictorio e incoherente.

Asimismo, en relación a la segunda premisa, es importante notar que el alcance de esta causal comprendía la interpretación de las normas, procedimientos o pruebas sobre las cuales la autoridad tributaria fijó una posición en la etapa de reclamación. Esta precisión es de la mayor relevancia, porque no es posible que la autoridad tributaria pueda alegar con motivo de la fundamentación de la pretensión impugnatoria de una RTF, un tema distinto al que sirvió de base para la correspondiente determinación de la obligación tributaria e imposición de sanciones.

Esta situación comentada se presentaría, entre otros supuestos, si al momento de presentar la demanda contenciosa administrativa, la Administración Tributaria realiza: la incorporación de un tema no discutido en la vía administrativa; y, un cambio de fundamento, precisamente por lo anterior, a la materia controvertida. Es decir, se presentaría: una afectación al rol resolutor

(40) Artículo 153: SOLICITUD DE CORRECCIÓN, AMPLIACIÓN O ACLARACIÓN:

Contra lo resuelto por el Tribunal Fiscal no cabe recurso alguno en la vía administrativa. No obstante, el Tribunal Fiscal, de oficio, podrá corregir errores materiales o numéricos, ampliar su fallo sobre puntos omitidos o aclarar algún concepto dudoso de la resolución, o hacerlo a solicitud de parte, (...) por la Administración Tributaria o por el deudor tributario (...). 
de máxima instancia previsto para el Tribunal Fiscal; y, entre otros aspectos, una afectación al derecho de defensa de los deudores tributarios.

(iii) Cuando exista dualidad de criterio del Tribunal Fiscal sobre la materia a demandar aún cuando se refiera a un contribuyente distinto.

El supuesto previsto en el numeral 3 del artículo 3 del Decreto Supremo 035-2004-EF, tiene dos (2) premisas para habilitar a la Administración Tributaria, previa autorización del MEF, para impugnar una RTF en la vía del proceso contencioso administrativo: (i) que la pretensión impugnatoria de la RTF se encuentre sustentada en un supuesto de dualidad de criterio del Tribunal Fiscal sobre la materia a demandar; y, (ii) que incluso sea posible que esa dualidad de criterio se haya producido con motivo de la emisión de RTF para contribuyentes distintos.

En relación a la primera premisa, es importante notar que, por su naturaleza, la duplicidad de criterio supone -para efectos de este supuesto- que el Tribunal Fiscal haya resuelto en forma diferente, en función a una misma base normativa, dos (2) supuestos de hecho iguales o similares. Es decir, nos encontramos ante la constatación de una labor interpretativa de resultados distintos para supuestos "iguales" por parte del Tribunal Fiscal. En este contexto, partiendo de la premisa que la autoridad tributaria no puede impugnar una RTF en la vía del proceso contencioso-administrativo, alegando una interpretación distinta de las normas, procedimientos o pruebas, consideramos que la alegación de esta causal debería haber generado en forma liminar la improcedencia de la correspondiente demanda.

No obstante, lo anterior, aceptando como posibilidad de análisis su procedencia, en atención a que nos encontramos ante un supuesto especial de legitimidad para obrar activa extraordinaria (en vía reglamentaria), una comprobación previa y necesaria que se tenía que realizar era que nos encontremos ante un supuesto de dualidad de criterio. No cualquier supuesto de dualidad de criterio, sino uno que: (i) califique propiamente como tal; y, (ii) sea de carácter manifiesto sobre la materia a impugnar.

A este efecto, nótese que aun cuando se acepte que una pretensión de nulidad de una RTF por la causal de dualidad de criterio debía ser evaluada, como tema de fondo, al momento de emitir sentencia, es importante resaltar que la apariencia de un supuesto de dualidad de criterio entre las distintas Salas del Tribunal Fiscal debía ser vista necesariamente al momento de evaluar la procedencia de la demanda.

De no ser así, es claro que, sobre la base de una mera alegación de una causal de dualidad de criterio, se podría haber admitido y emitido pronunciamiento sobre demandas contenciosas administrativas que contenían pretensiones de nulidad de una RTF sobre la base de diferencias interpretativas entre la SUNAT y el Tribunal Fiscal, pero no propiamente diferencias interpretativas de las Salas Especializadas de este propio órgano resolutor de máxima instancia. En otros términos, se hubiera excedido los alcances del presente puesto previsto por ley.

Hecha la precisión anterior, y asumiendo como legalmente posible que se impugne una RTF por la causal de dualidad de criterio, su acogimiento solo hubiera tenido efectos nulificantes. En otros términos, frente a la constatación -como en efecto ocurre-, objetiva y manifiesta, que el Tribunal Fiscal haya incurrido en dualidad de criterio al momento de resolver dos (2) controversias iguales o similares, incluso así sean de dos (2) deudores tributarios distintos, la Administración Tributaria podría solicitar en su oportunidad al Poder Judicial que se declare la nulidad de la correspondiente RTF. Esto, con el propósito que se ordene que el expediente regrese a la instancia administrativa, el Tribunal Fiscal asuma nuevamente competencia y, sobre esa base, defina el criterio que debe prevalecer, conforme a lo previsto en el segundo párrafo del artículo 154 del Código Tributario(41).

En relación a la segunda premisa, es importante advertir que la alegación de la causal de dualidad de criterio no se limita al supuesto previsto en que se trata del mismo contribuyente, sino que está previsto en

(41) Artículo 154: JURISPRUDENCIA DE OBSERVANCIA OBLIGATORIA:

(...)

De presentarse nuevos casos o resoluciones con fallos contradictorios entre sí, el Presidente del Tribunal deberá someter a debate en Sala Plena para decidir el criterio que deba prevalecer, constituyendo éste precedente de observancia obligatoria en las posteriores resoluciones emitidas por el Tribunal.

La resolución a que hace referencia el párrafo anterior así como las que impliquen un cambio de criterio, deberán ser publicadas en el Diario Oficial.

(...). 
forma abierta, comprendiendo incluso supuestos en los que el Tribunal Fiscal haya tenido diferencia interpretativa entre dos (2) contribuyentes distintos. Esto, toda vez que la dualidad de criterio no está siendo analizada desde el punto de vista del contribuyente como solicitante (supuesto en el cual se puede pensar que la diferencia de criterio se debe presentar en dos situaciones del propio contribuyente), sino del Tribunal Fiscal como órgano resolutor de controversias en última instancia administrativa.

Como se puede apreciar de la regulación prevista en el texto del artículo 157 del Código Tributario, modificado por el Decreto Legislativo 953, y su norma reglamentaria, se reconocía expresamente que la Administración Tributaria tiene la posibilidad de impugnar una RTF en la vía del proceso contencioso administrativo, sujeto a la autorización del MEF.

Esta situación viene a evidenciar legalmente que la Administración Tributaria, en tanto no es el acreedor tributario, no tenía legitimidad para obrar activa ordinaria (titular del derecho material involucrado), sujetando su actuación a lo dispuesto por el MEF, en función a los supuestos previstos en el Decreto Supremo 035-2004-EF, los mismos que en el mejor de los casos responden a la naturaleza de pretensiones de mero control de legalidad.

\subsection{Acerca de la modificación prevista por la Ley 28365}

El 24 de octubre de 2004, fue publicada en el Diario Oficial El Peruano la Ley $28365^{(42)}$. En virtud del artículo 1 de la mencionada ley, se sustituyó el texto del artículo 157 del Código Tributario -incorporado en su oportunidad por el Decreto Legislativo 953-, en los términos que se indican a continuación:

Artículo 157: Demanda Contencioso Administrativa:

La resolución del Tribunal Fiscal agota la vía administrativa. Dicha resolución podrá impugnarse mediante el Proceso Contencioso Administrativo, el cual se regirá por las normas contenidas en el presente Código y, supletoriamente, por la Ley $N^{\circ} 27584$, Ley que regula el Proceso Contencioso Administrativo.

La demanda podrá ser presentada por el deudor tributario ante la Sala Contencioso Administrativa de la Corte Superior respectiva, dentro del término de tres (3) meses computados a partir del día siguiente de efectuada la notificación de la resolución debiendo contener peticiones concretas.

La presentación de la demanda no interrumpe la ejecución de los actos o resoluciones de la Administración Tributaria.

La Administración Tributaria no tiene legitimidad para obrar activa. De modo excepcional, la Administración Tributaria podrá impugnar la resolución del Tribunal Fiscal que agota la vía administrativa mediante el Proceso Contencioso Administrativo en los casos en que:

a) Exista dualidad de criterio entre las distintas Salas del Tribunal Fiscal sobre la materia a demandar, aun cuando se refiera a un contribuyente distinto; o, b) La resolución del Tribunal Fiscal no se haya emitido por unanimidad de los votos en la Sala correspondiente; 0 ,

c) La resolución del Tribunal Fiscal incurra en una de las causales de nulidad previstas en el artículo 10 de la Ley $N^{\circ} 27444$, Ley del Procedimiento Administrativo General.

Tratándose de la SUNAT requerirá adicionalmente, autorización previa del Ministro de Economía y Finanzas para interponer la demanda contencioso administrativa a que hubiera lugar.

Por decreto supremo, refrendado por el Ministro de Economía y Finanzas, se procederá a reglamentar lo señalado en los dos párrafos precedentes (énfasis agregado).

Según se puede apreciar, el artículo 157 del Código Tributario, modificado por Ley 28365 , sigue partiendo de las mismas premisas que la modificación prevista por el Decreto Legislativo 953. Esto es, se establece que: (i) la RTF agota la vía administrativa; (ii) la impugnación de una RTF se puede impugnar mediante el proceso contencioso-administrativo, conforme a las normas del Código Tributario $y$, supletoriamente, por la LPCA; (iii) el plazo para que el deudor tributario interponga la demanda contencioso-administrativo es de tres (3) meses, computados a partir del día siguiente de la notificación de la RTF; (iv) la demanda debe contener peticiones concretas; (v) la Administración Tributaria no podía impugnar una RTF que haya establecido jurisprudencia de observancia obligatoria; (vi) la competencia funcional le correspondía a la Sala Contenciosa Administrativa de la Corte Superior respectiva; y, (vii) la interposición de la demanda no interrumpe la ejecución de los actos o resoluciones de la Administración Tributaria.

Sin embargo, un primer aspecto para advertir es que el texto del artículo 157 del Código Tributario, modificado por Ley 28365 , no establecía expresamente el plazo para que la Administración Tributaria interponga la demanda contencioso-administrativa tributaria con motivo de la notificación de una RTF.

Solo se indicaba específicamente que el plazo de tres (3) meses para demandar

(42) En vigencia desde el 25 de octubre de 2004. 
correspondía al deudor tributario. En ese sentido, era de aplicación supletoria a dicha situación la LPCA, la cual establece que el plazo general para interponer demanda contencioso-administrativa es de tres (3) meses contados desde la misma fecha de notificación de la $\operatorname{RTF}^{(43)}$. Este es un aspecto de particular relevancia, porque el inicio del cómputo para interponer la demanda por el deudor tributario y la Administración Tributaria, no eran iguales. Mientras el plazo para demandar a cargo del deudor tributario, era tres (3) meses desde el día siguiente de notificada la RTF, en el caso de la Administración Tributaria es de tres (3) meses desde el mismo día de notificada la RTF.

Un segundo aspecto a considerar, es que el artículo 157 del Código Tributario, modificado por la Ley 28365, viene a establecer en forma expresa que la Administración Tributaria no tiene legitimidad para obrar activa.

Esta situación es de particular importancia, como se ha visto en puntos previos, porque parte por reconocer que en nuestra propia legislación tributaria: (i) el acreedor tributario es el titular en favor del cual se cumple la prestación tributaria; y, (ii) la SUNAT, como su propia denominación lo indica, es una entidad administradora de los tributos internos y arancelarios. Sobre la base de lo anterior, se advierte entonces que, si la legitimidad para obrar supone reconocer en la relación procesal a quien es titular de la relación material, la Administración Tributaria -en tanto no es el acreedor tributario-, no tiene propia y técnicamente legitimidad para obrar activa ordinaria. En ese sentido, se ha señalado que:

La legitimación activa no le corresponde a la SUNAT sino al acreedor tributario que, en el caso de tributos nacionales, es el Ministerio de Economía y Finanzas. Sin embargo, a pesar que el Código Tributario reconoce esta falta de legitimidad, le otorga la facultad de interponer demandas contenciosas-administrativas cuando la resolución del Tribunal Fiscal adolezca de alguna causal de nulidad (Robles, 2015, p. 789).

Un tercer aspecto, derivado precisamente de lo anterior, es que el texto del artículo 157 del Código Tributario, modificado por la Ley 28365, establecía que la Administración Tributaria no tiene legitimidad para obrar activa. Sin embargo, también se establece que la Administración Tributaria tiene la posibilidad de impugnación de una RTF, en forma excepcional.

Como se ha señalado, en virtud de esta modificación, se viene a reconocer legislativamente que la Administración Tributaria no es titular del derecho material en controversia. Sin embargo, se reconoce la posibilidad que la Administración
Tributaria pueda demandar una RTF en los supuestos previstos expresamente por el artículo 157 del Código Tributario. Es decir, como se ha explicado en líneas previas, nos encontramos ante una legitimidad para obrar activa de naturaleza extraordinaria. También se ha señalado que:

La Administración Tributaria puede impugnar actos del Tribunal Fiscal cuando incurra en alguna de las causales de nulidad del artículo $10^{\circ}$ de la Ley 27444 . Esto, es preciso señalarlo, no es un proceso de agravio, sino una prescripción especial donde la Ley faculta a la Administración Tributaria a impugnar o solicitar judicialmente la declaración de nulidad de un acto expedido por otro órgano de la Administración Tributaria, en puridad, el máximo órgano de la "jurisdicción administrativa" tributaria. En este caso, la SUNAT tendrá "legitimación activa extraordinaria" prevista por Ley para impugnar un acto del Tribunal Fiscal, pero insistimos, esto no es un proceso de agravio (toda vez que la SUNAT no busca la nulidad de un acto propio), sino de un caso concreto de legitimación activa extraordinaria prevista por ley (Huapaya, 2010, p. 98).

Un cuarto aspecto a considerar, es que el artículo 157 del Código Tributario, modificado por la Ley 28365 , establece que en forma excepcional la Administración Tributaria podrá impugnar una RTF mediante la interposición de la correspondiente demanda contenciosa administrativa, en los supuestos previstos a tal efecto.

Toda vez que se trata de supuestos de excepción a la regla general (que puedes impugnar solo por mandato de la ley, y no porque eres titular del derecho material involucrado), consideramos que los mismos deben interpretarse en forma restrictiva, no pudiendo extenderse o crearse supuestos no previstos por ley. Es decir, en el supuesto que se presente una posible duda en la interpretación de la disposición en mención, respecto a si un supuesto está regulado o, asumiendo que está regulado, si su alcance excede el previsto por ley, la conclusión nos

(43) Artículo 18: PLAZOS:

La demanda deberá ser interpuesta dentro de los siguientes plazos:

1. Cuando el objeto de la impugnación sean las actuaciones a que se refieren los numerales 1, 3, 4, 5 y 6 del artículo 4 , el plazo será de tres meses a contar desde el conocimiento o notificación de la actuación impugnada, lo que ocurra primero. (...). 
debería llevar a señalar que no está regulado o excede el alcance de la ley.

Un quinto aspecto a considerar, derivado de lo señalado en el punto anterior, es que el cuarto párrafo del artículo 157 del Código Tributario, modificado por la Ley 28365, dispone expresamente que la Administración Tributaria podrá impugnar la correspondiente RTF.

En atención a que la Administración Tributaria: (i) no tiene legitimidad para obrar activa ordinaria (por ejemplo, no es titular del derecho material en controversia); (ii) solo tiene legitimidad para obrar activa extraordinaria (por ejemplo, en función a lo previsto en los alcances de la ley de autorización); (iii) que la legitimidad para obrar activa extraordinaria autorizada, por su naturaleza y en los términos que ha sido prevista, es excepcional (por ejemplo, se debe aplicar en forma restrictiva la ley de autorización, no pudiendo extenderse o crearse supuestos no previstos por ley); debemos entender que la previsión legal para interponer una demanda contenciosa administrativa solo se limita a impugnar la RTF. Es decir, mediante la impugnación de una RTF no debía ser posible obtener, en forma accesoria -por ejemplo-, la confirmación de los reparos u observaciones formuladas por la Administración Tributaria en los actos administrativos tributarios (por ejemplo, orden de pago, resolución de determinación, resolución de multa).

Un sexto aspecto a comentar, es que el artículo 157 del Código Tributario, modificado por la Ley 28365 , es el texto que establece en forma directa y expresa los supuestos en los cuales la Administración Tributaria podrá impugnar una RTF.

Es decir, a diferencia de lo que ocurría con el texto del artículo 157 del Código Tributario, incorporado por el Decreto Legislativo 153, en el que una norma reglamentaria (por ejemplo, el Decreto Supremo 035-2004-EF), estableció los criterios en virtud de los cuales el MEF podía autorizar a la SUNAT para impugnar una RTF, ahora una norma con rango de ley establece la regulación para tal posibilidad. Se evita así, cualquier situación de cuestionamiento a la legalidad de la actuación de la autoridad tributaria al impugnar la correspondiente RTF en la vía del proceso contencioso administrativo. Ahora bien, en cuanto al alcance material de los supuestos previstos en el artículo 157 del Código Tributario, modificado por la Ley 28365; que, de modo excepcional, permitían que se autorice a la Administración Tributaria a impugnar una RTF en la vía del proceso contencioso administrativo, se puede destacar lo siguiente:

(i) Exista dualidad de criterio entre las distintas salas del Tribunal Fiscal sobre la materia a demandar, aun cuando se refiera a un contribuyente distinto.
La causal prevista en el literal a) del cuarto párrafo del artículo 157 del Código Tributario, modificado por la Ley 28365 , se trata de un supuesto similar al regulado, en su oportunidad, en el numeral 3 del artículo 3 del Decreto Supremo 035-2004-EF, norma reglamentaria del artículo 157 del Código Tributario, según el texto incorporado introducido por el Decreto Legislativo 953. En ese sentido, nos remitimos para todos los efectos a lo comentado en líneas previas en relación al numeral 3 del artículo 3 del Decreto Supremo 035-2004-EF.

(ii) La resolución del Tribunal Fiscal no se haya emitido por unanimidad de los votos en la Sala correspondiente.

A fin de entender el sentido de la causal prevista en el literal b) del cuarto párrafo del artículo 157 del Código Tributario, modificado por la Ley 28365 , cabe indicar que en nuestra legislación el funcionamiento de las Salas Especializadas del Tribunal Fiscal requiere -como regla general-, lo siguiente: la concurrencia (quórum) de tres (3) vocales; y, el voto de (dos) vocales, en el mismo sentido (mayoría), para que se entienda emitida formalmente una resolución $n^{(44)}$.

Establecida la premisa normativa anterior, el supuesto de hecho de esta causal era que en la demanda contenciosa administrativa se impugne: una RTF que se haya emitido para resolver un procedimiento administrativo tributario a cargo del Tribunal Fiscal; y, para la emisión de la RTF, dos (2) vocales votaron en un sentido, y un (1) vocal votó en otro sentido.

Según se puede apreciar, nos encontramos ante un supuesto de diferencia de criterio interpretativo que hubieran tenido los vocales del Tribunal Fiscal al momento de resolver un caso. No establece esta disposición (a diferencia de lo que ocurre con el supuesto previsto en el literal c) del cuarto párrafo del artículo 157 del Código Tributario, modificado por la Ley 28365), una habilitación legal específica en otro sentido.

(44) Artículo 101: FUNCIONAMIENTO Y ATRIBUCIONES DEL TRIBUNAL FISCAL:

Las Salas del Tribunal Fiscal se reunirán con la periodicidad que se establezca por Acuerdo de Sala Plena. Para su funcionamiento se requiere la concurrencia de los tres (3) vocales y para adoptar resoluciones, dos (2) votos conformes (...). 
En este orden de ideas, en atención a los alcances de la potestad otorgada a la Administración Tributaria y del supuesto de hecho en análisis, consideramos que nos encontramos ante una causal de naturaleza meramente anulatoria. Esto supone que en caso el órgano judicial correspondiente declare, en forma definitiva y favorable a la pretensión formulada, que se ha producido falta de unanimidad al momento de emitir una RTF, el expediente debía regresar a la instancia administrativa con la finalidad que esta entidad resolutora determine si en esta discrepancia existe o una contravención a la ley.

(iii) La resolución del Tribunal Fiscal incurra en una de las causales de nulidad previstas en el artículo 10 de la Ley 27444 - Ley del Procedimiento Administrativo General.

La causal prevista en el literal c) del cuarto párrafo del artículo 157 del Código Tributario, modificado por la Ley 28365, establece que la Administración Tributaria podrá impugnar una RTF, cuando esta incurra en alguna de las causales de nulidad previstas en el artículo 10 de la Ley del Procedimiento Administrativo General, aprobada por Ley 27444, cuyo Texto Único Ordenado fue aprobado por Decreto Supremo 004-2019JUS (en adelante, “LPAG”)(45).

Al respecto, es importante señalar que la incorporación del literal c) del cuarto párrafo del artículo 157 del Código Tributario, modificado por la Ley 28365, fue la primera oportunidad en la que el legislador nacional estableció una regulación expresa y específica -por remisión- de diversas causales propiamente de nulidad que habilitaban a la Administración Tributaria para impugnar una RTF mediante la interposición de la correspondiente demanda contenciosa administrativa. Así, según se puede apreciar en el texto del artículo 10 de la LPAG, se establecieron como causales de nulidad, entre otros supuestos: (i) la contravención a la Constitución Política, a las leyes o a las normas reglamentarias; y, (ii) el defecto o la omisión de alguno de sus requisitos de validez del acto administrativo.

Nótese que incurrir en alguno de los supuestos previstos en la disposición legal en mención, supone la nulidad de pleno derecho del acto administrativo correspondiente (ejemplo, la RTF). Esta declaración de nulidad, conforme a lo previsto en el artículo 12 de la LPAG, tenía y tiene efecto declarativo y retroactivo a la fecha de emisión del acto nulo ${ }^{(46)}$. A fin de evitar que, a través de una pretensión de nulidad de una RTF, sobre la base de una de las causales previstas en el artículo 10 de la LPAG, se pretenda cuestionar el criterio interpretativo que tuvo el Tribunal Fiscal al momento de emitir el acto administrativo impugnado, se debía entender que la nulidad que alegue y acredite la Administración Tributaria debe ser manifiesta, insubsanable y trascendente ${ }^{(47)}$. En caso no sea así, la demanda correspondiente deberá ser declarada infundada.

Esta situación ha sido corroborada y corregida legislativamente a la fecha mediante el artículo 2 del Decreto Legislativo $1272^{(48)}$, que modificó el artículo 6 de la LPAG ${ }^{(49)}$. En virtud a esta disposición, se establece que no constituye causal de nulidad la apreciación distinta que tenga el superior jerárquico (por ejemplo, Tribunal Fiscal), en relación a la valoración de los medios probatorios, a la aplicación o interpretación de la ley establecida en el acto administrativo

(45) Artículo 10.- Causales de nulidad:

Son vicios del acto administrativo, que causan su nulidad de pleno derecho, los siguientes:

1. La contravención a la Constitución, a las leyes o a las normas reglamentarias.

2. El defecto o la omisión de alguno de sus requisitos de validez, salvo que se presente alguno de los supuestos de conservación del acto a que se refiere el artículo 14.

3. Los actos expresos o los que resulten como consecuencia de la aprobación automática o por silencio administrativo positivo, por los que se adquiere facultades, o derechos, cuando son contrarios al ordenamiento jurídico, o cuando no se cumplen con los requisitos, documentación o tramites esenciales para su adquisición.

4. Los actos administrativos que sean constitutivos de infracción penal, o que se dicten como consecuencia de la misma.

(46) Artículo 12.- Efectos de la declaración de nulidad

12.1 La declaración de nulidad tendrá efecto declarativo y retroactivo a la fecha del acto, salvo derechos adquiridos de buena fe por terceros, en cuyo caso operará a futuro.

(47) Respecto a la procedencia de la declaración de la nulidad, véase Huapaya, R. (2006). Tratado del Proceso Contencioso-Administrativo (p. 852). Jurista Editores.

(48) Publicado en el Diario Oficial El Peruano el 21 de diciembre de 2016, entrando en vigencia al día siguiente de su publicación.

(49) Artículo 6.- Motivación del acto administrativo

(...)

No constituye causal de nulidad el hecho de que el superior jerárquico de la autoridad que emitió el acto que se impugna tenga una apreciación distinta respecto de la valoración de los medios probatorios o de la aplicación o interpretación del derecho contenida en dicho acto. Dicha apreciación distinta debe conducir a estimar parcial o totalmente el recurso presentado contra el acto impugnado. 
impugnado. Ahora bien, continuando con esta secuencia de ideas, toda vez que el literal c) del cuarto párrafo del artículo 157 del Código Tributario, modificado por la Ley 28365, estableció que la Administración Tributaria podía impugnar una RTF, cuando ésta incurra en alguna de las causales de nulidad previstas en el artículo 10 de la LPAG, esta situación generó la vinculación y habilitación, precisamente por lo anterior, para la formulación de pretensiones de declaración de nulidad de los actos administrativos, conforme a lo previsto en el numeral 1 del artículo 5 de la LPCA $^{(50)}$.

Como correlato de lo anterior, en virtud a este literal c) en mención, no se estableció una potestad en favor de la Administración Tributaria para que alegue pretensiones de plena jurisdicción (control subjetivo). Esto, en nuestra opinión, en la línea de guardar coherencia entre el texto previsto en el literal c) en mención, con la introducción del cuarto párrafo del artículo 157 del Código Tributario, modificado por la Ley 28365, que establece una legitimación para obrar activa extraordinaria para la Administración Tributaria.

Cierto, como se ha explicado en puntos previos, en atención a que: (i) la Administración Tributaria no tiene legitimidad para obrar activa ordinaria (por ejemplo, no es titular del derecho material en controversia); (ii) solo tiene legitimidad para obrar activa extraordinaria (por ejemplo, en función a lo previsto en los alcances de la ley de autorización); (iii) la legitimidad para obrar activa extraordinaria autorizada, por su naturaleza y en los términos que ha sido prevista, es excepcional. ${ }^{(51)}$ (por ejemplo, se debe aplicar en forma restrictiva la ley de autorización, no pudiendo extenderse o crearse supuestos no previstos por ley); consideramos que la autorización legal prevista en dicha oportunidad solo permitía interponer una demanda contenciosa administrativa para solicitar la nulidad de la RTF. Es decir, solo se habilitó a la Administración Tributaria la alegación de pretensiones de mero control de legalidad. Comentando la naturaleza de esta pretensión, se ha señalado que a través de la misma se:

(...) acude al órgano jurisdiccional con la finalidad de que éste realice un control de legalidad de una actuación administrativa, con la particularidad que la competencia del órgano jurisdiccional se limitará a realizar una declaración de nulidad de la actuación administrativa impugnada. Es por ello que en este caso nos encontramos ante una pretensión meramente declarativa (Priori, 2002, p. 150).
En concreto, comentando la pretensión prevista en el numeral 1 del artículo 5 de la LPCA, se ha señalado que esta es:

(...) la tradicional pretensión de anulación que parte de concebir como presupuesto de la actuación jurisdiccional, una actuación administrativa expresada a través de un acto administrativo que, sin embargo, incurre en una de las causales de nulidad establecidas en la Ley del Procedimiento Administrativo General. Ante ello, se recurre al órgano jurisdiccional para que éste realice una mera revisión de la legalidad del acto, luego de la cual, a través de una sentencia, declarará si dicho acto es o no, contrario a derecho (Priori, 2002, pp. 152-153).

No era posible, entonces, conforme a esta normativa, que la Administración Tributaria pueda formular pretensiones de reconocimiento del tratamiento tributario que estableció en el acto administrativo tributario que emitió en su oportunidad (plena jurisdicción).

A este efecto, no era ni es posible alegar la aplicación supletoria del artículo 11 (ahora 13) de la LPCA, para sostener válidamente que la Administración Tributaria podía formular pretensiones de plena jurisdicción. Esto, como hemos visto en líneas previas, porque el primer párrafo de esta disposición solo es aplicable a sujetos que son titulares del derecho material involucrado (situación que no cumple la Administración Tributaria, en tanto no es el acreedor tributario). Asimismo, tampoco era posible alegar válidamente la aplicación supletoria del segundo párrafo del artículo 11 (ahora 13) de la LPCA, toda vez que este está previsto para el proceso de lesividad, supuesto que no se cumple porque la Administración Tributaria no es la propia entidad administrativa que emite las RTF. En todo caso, porque este párrafo condiciona su aplicación a lo facultado por ley.

(50) Artículo 5: Pretensiones:

En el proceso contencioso administrativo podrán plantearse pretensiones con el objeto de obtener lo siguiente:

1. La declaración de nulidad, total o parcial o ineficacia de actos administrativos.

(...)

(51) Al respecto, véase la Sentencia de Casación No. 4843-2012 LIMA, publicada en el Diario Oficial El Peruano el 9 de noviembre de 2020. En concreto, se indicó que la Administración Tributaria involucrada se encuentra "(...) habilitada para interponer la demanda contencioso administrativa contra el Tribunal Fiscal en aplicación del artículo 157 del Código Tributario, ya que de manera excepcional le otorga legitimidad para obrar activa a fin de que la administración municipal pueda entrar impugnar lo resuelto por el Tribunal Fiscal en el supuesto que considere que se ha incurrido en alguna de las causales de nulidad previstas en el artículo 10 de la Ley número 27444". 
Nótese que, para establecer los alcances de la legitimidad para obrar activa de la Administración Tributaria para impugnar una RTF en la vía del proceso contencioso administrativo, se debe partir de una interpretación objetiva y conforme a la ley, según el texto vigente en cada momento en nuestro ordenamiento jurídico. No es posible, sobre la base de alegar la prevalencia de un deber de contribuir -como máxima general-, interpretar las leyes sin sujetarse ni considerar lo previsto expresamente en nuestro ordenamiento jurídico.

En efecto, no queda duda que en todo Estado Constitucional de Derecho -que se autodenomine así y respete el orden constitucional y democrático sustancial-, toda actuación de la autoridad pública está sujeta a la ley. En ese sentido, la vigencia material del deber de contribuir no puede ni debe ser entendida, para efectos tributarios, como fundamento per se -tanto para emitir normas como para aplicar las mismas, en forma directa o indirecta- para pretender que se tutele un interés recaudatorio. En ese sentido, se ha señalado que:

Ello es especialmente importante en el concreto ámbito del Derecho Tributario, donde el interés público que le caracteriza como rama del Derecho Público es (...) procurar al Estado los medios económicos necesarios para el ejercicio de su actividad (...). Estaríamos aquí ante el llamado (...) interés recaudatorio. Pero es evidente que este interés recaudatorio no puede prevalecer por sí solo frente a la seguridad jurídica ni puede, por lo tanto, erigirse en límite de ésta (García, 2000, p. 86).

En tal caso, es ilegal e inconstitucional partir de una premisa de interpretación, directa o indirecta, pro fisco ${ }^{(52)}$. En estricto, entendido en forma correcta, la protección del deber de contribuir supone que el ejercicio de las potestades por parte de la Administración Tributaria sean producto de lo previsto por la ley.

Por tal motivo, conforme al texto del literal c) del cuarto párrafo del artículo 157 del Código Tributario, modificado por la Ley 28365 , consideramos que era necesario que el legislador nacional estableciera en forma expresa -en caso sea posible, conforme a su naturaleza y a la estructura del procedimiento tributario- la potestad de la Administración Tributaria no solo de formular pretensiones de nulidad (control de legalidad), sino también pretensiones de plena jurisdicción, conforme a lo previsto en forma específica y diferenciada en el numeral 2 del referido artículo 5 de la LPCA $^{(53)}$.

El 2 de diciembre de 2004, fue publicado en el Diario Oficial El Peruano el Decreto Supremo 166-2004-EF. Mediante este decreto, se establecieron disposiciones reglamentarias de autorización previa del MEF a la SUNAT para impugnar una RTF que agota la vía administrativa, conforme a lo previsto en el artículo 157 del Código Tributario, modificado por la Ley 28365.

En concreto, mediante el Decreto Supremo 166-2004-EF, se estableció que: (i) la SUNAT debía solicitar la autorización previa al MEF en un plazo no mayor de cuarenta y cinco (45) días calendario contados desde la fecha de notificación de la RTF a dicha entidad; (ii) la solicitud de la SUNAT referida en el punto (i) previo, debía contar con un informe legal de sustento emitido por la Intendencia Nacional Jurídica de la propia entidad; (iii) la autorización previa del MEF procedía siempre que se contara con el informe favorable de la Defensoría del Contribuyente y Usuario Aduanero, el cual debía ser remitido dentro del plazo previsto en el literal b) del artículo 2 del Decreto Supremo 050-2004EF(54); (iv) la demanda debía ser presentada ante la Sala Contencioso Administrativa de la Corte Superior respectiva ${ }^{(55)}$, dentro del término

(52) Al respecto, véase Giannini, A. (1957). Instituciones de Derecho Tributario. (pp. 31-32). Editorial de Derecho Financiero; Vanoni, E. (1973). Naturaleza e interpretación de las leyes tributarias. (p. 217). Instituto de Estudios Fiscales; Berliri, A. (1964). Principios de Derecho Tributario (vol. I). (p. 96). Editorial de Derecho Financiero; García, F. (2001). Derechos y garantías constitucionales en los procedimientos tributarios. Situación actual y perspectivas de evolución. En F. García, Derecho Financiero Constitucional (pp. 268-270). Civitas Ediciones.

(53) Artículo 5: Pretensiones:

En el proceso contencioso administrativo podrán plantearse pretensiones con el objeto de obtener lo siguiente:

(...)

2. El reconocimiento o restablecimiento del derecho o interés jurídicamente tutelado y la adopción de las medidas o actos necesarios para tales fines.

(54) El literal e) del artículo 1 del Decreto Supremo 050-2004-EF estableció que constituye función del Defensor del Contribuyente y del Usuario Aduanero, entre otras, "informar al Ministerio de Economía y Finanzas sobre la procedencia o no de las solicitudes que formule Sunat para interponer demandas contencioso-administrativas contra resoluciones del Tribunal Fiscal". Para el cumplimiento de la función antes indicada, el literal b) del artículo 2 del referido Decreto Supremo, estableció que para la emisión del informe a que se refiere el literal e) del artículo 1, el plazo era de 30 días calendario.

(55) Conforme al texto original del segundo párrafo del artículo 11 de la LPCA, la competencia funcional para la impugnación de Resoluciones del Tribunal Fiscal era: (i) en primera instancia, la Sala Contenciosa Administrativa de la Corte Superior respectiva; (ii) en segunda instancia, la Sala Civil de la Corte Suprema; y, (iii) en casación, la Sala Constitucional y Social. 
de los tres (3) meses computados a partir del día siguiente de efectuada la notificación de la resolución; y, (v) la autorización del MEF para presentar la demanda debía ser exteriorizada a través de la correspondiente Resolución Ministerial(56).

Como se puede apreciar de la regulación prevista en el artículo 157 del Código Tributario, modificado por la Ley 28365, y su norma reglamentaria, se reconoce por primera vez a nivel legal que la Administración Tributaria no tiene legitimidad para obrar activa ordinaria. Solo puede impugnar una RTF en los supuestos previstos por ley (legitimidad para obrar extraordinaria), en los cuales se advierte por primera vez la referencia -por remisión- a causales de nulidad (control de legalidad), conforme a lo previsto en el numeral 1 del artículo 5 de la LPCA. Sin embargo, no se le facultó a formular pretensiones de plena jurisdicción, conforme a lo previsto en el numeral 2 del artículo 10 de la LPCA.

\subsection{Acerca de la modificación prevista por el Decreto Legislativo 981 \\ El 15 de marzo de 2007, fue publicado en el Diario Oficial El Peruano el Decreto Legislativo 981(57), mediante el cual se modificaron diversas disposiciones del Código Tributario vigente.}

Así, entre otras disposiciones, mediante el artículo 39 del referido Decreto Legislativo 981, se modificó el cuarto párrafo del artículo 157 del Código Tributario, en los siguientes términos:

La Administración Tributaria no tiene legitimidad para obrar activa. De modo excepcional, la Administración Tributaria podrá impugnar la resolución del Tribunal Fiscal que agota la vía administrativa mediante el Proceso Contencioso Administrativo en los casos en que la resolución del Tribunal Fiscal incurra en alguna de las causales de nulidad previstas en el artículo 10 de la Ley 27444. Ley del Procedimiento Administrativo General [énfasis agregado].

Según se puede apreciar, en virtud a la modificación introducida por el Decreto Legislativo 981, se mantiene la estructura del texto del cuarto párrafo del artículo 157 del Código Tributario, modificado por la Ley 28365.

La diferencia básicamente se encuentra en la eliminación de las causales previstas en los literales a) y b), referidas a las causales de duplicidad de criterio y falta de unanimidad en los votos al momento de resolver por parte de las Salas del Tribunal Fiscal, respectivamente.

En relación a la autorización legal para que la Administración Tributaria impugne una RTF, en la vía del proceso contencioso administrativo, cuando se haya incurrido en alguna de las causales previstas en el artículo 10 de la LPAG, el texto normativo es el mismo que el previsto en el literal c) del cuarto párrafo del artículo 157 del Código Tributario, modificado por la Ley 28365.

En ese sentido, nos remitimos a los alcances normativos referidos en el punto 9 del apartado previo del presente trabajo. Asimismo, consideramos conveniente destacar que la modificación introducida por el Decreto Legislativo 981, viene a reconocer legalmente que las causales previstas en el literal a) y b) del cuarto párrafo del artículo 157 del Código Tributario, modificado por la Ley 28365 , en estricto recogían supuestos de diferencia interpretativa al momento de resolver y emitir una RTF por parte de las Salas Especializadas del Tribunal Fiscal. Es decir, por su propia naturaleza, conforme se ha explicado en líneas previas, no calificaban incluso como causales de nulidad de una Resolución del Tribunal Fiscal. En estos casos, se tenía que estar sujeto a lo que había resuelto en su momento el Tribunal Fiscal.

Siguiendo esta línea de explicación, cabe indicar que mediante la Única Disposición Complementaria Derogatoria del Decreto Legislativo 981, se derogó -entre otras disposiciones-, el quinto y sexto párrafo del artículo 157 del Código Tributario, modificado por la Ley 28365. Así, conforme a esta disposición, se derogó los siguientes textos del artículo 157 del Código Tributario:

(...) Tratándose de la SUNAT requerirá, adicionalmente, autorización previa del Ministro de Economía y Finanzas para interponer la demanda contencioso administrativa a que hubiera lugar.

Por Decreto Supremo, refrendado por el Ministro de Economía y Finanzas, se procederá a reglamentar lo señalado en los dos párrafos precedentes.

Como se puede apreciar, en virtud de la Única Disposición Complementaria

(56) Mediante la Cuarta Disposición Complementaria Final de la Ley 28969, publicada en el Diario Oficial El Peruano el 25 de enero de 2007, entrando en vigencia al día siguiente de su publicación, se estableció una excepción al quinto párrafo del artículo 157 del Código Tributario, modificado por la Ley 28365. Así, se dispuso que la interposición de demandas contenciosas administrativas en materia de regalías mineras, no se encontraba sujeta a autorización previa el MEF.

(57) Conforme a la Primera Disposición Complementaria Final del Decreto Legislativo 981, este cuerpo legal entró en vigencia -como regla general- el 1 de abril de 2007. 
Derogatoria del Decreto Legislativo 981, se ha eliminado la sujeción que tenía la Administración Tributaria de obtener autorización previa del Ministerio de Economía y Finanzas para interponer la correspondiente demanda contenciosa administrativa.

Esta derogación específica y expresa es de particular importancia, porque desde el 1 de abril de 2007 la Administración Tributaria se encuentra formalmente habilitada en forma directa para impugnar una RTF mediante una demanda contenciosa administrativa. Solo tendría que alegar y acreditar que la correspondiente RTF se encuentra en alguno de los supuestos previstos en el artículo 10 de la LPAG. Sin embargo, aun cuando se haya eliminado la sujeción de la Administración Tributaria para impugnar una RTF a la autorización previa del MEF, esta situación no cambia, incluso más allá de su reconocimiento legal o no: (i) la naturaleza de su legitimidad para obrar activa (de naturaleza extraordinaria, por no ser titular del derecho material involucrado, en tanto no es el acreedor tributario); $y$, (ii) que el ejercicio de su potestad para impugnar una RTF está sujeta a lo previsto legalmente a la fecha, comprendiendo la habilitación legal la formulación de pretensiones de mero control de legalidad, conforme a lo previsto en el numeral 1 del artículo 5 de la LPCA.

Como se puede apreciar de la regulación prevista en el artículo 157 del Código Tributario, modificado por el Decreto Legislativo 981, se sigue reconociendo que la Administración Tributaria no tiene legitimidad para obrar activa de naturaleza ordinaria. Solo puede impugnar una RTF, con motivo de la alegación y acreditación de los supuestos de nulidad previstos en el artículo 10 de la LPAG. No puede alegar el reconocimiento de una situación jurídica material, producto de lo anterior, conforme a lo previsto en el numeral 2 del artículo 5 de la LPCA.

\subsection{Acerca de la modificación prevista por el Decreto Legislativo 1121}

El 18 de julio de 2012, fue publicado en el Diario Oficial El Peruano el Decreto Legislativo 1121(58). Conforme al artículo 4 del mencionado Decreto Legislativo, se sustituyó el texto del segundo párrafo del artículo 157 del Código Tributario, modificado en su momento por la Ley 28365, en los términos que se indican a continuación:

(...) La demanda podrá ser presentada por el deudor tributario ante la autoridad judicial competente, dentro del término de tres (3) meses computados a partir del día siguiente de efectuada la notificación de la resolución debiendo contener peticiones concretas (énfasis propio).
Al respecto, es importante destacar que, en virtud a esta modificación, se eliminó la referencia prevista a la "Sala Contenciosa Administrativa de la Corte Superior", como órgano con competencia funcional para conocer las impugnaciones de Resoluciones del Tribunal Fiscal mediante demandas contenciosas administrativas. En su lugar, se estableció la referencia a "la autoridad judicial competente", a fin que la competencia se encuentre sujeta al tratamiento que establezca la LPCA ${ }^{(59)}$.

\section{Alcances normativos del texto vigente del Artículo 157 del Código Tributario}

A la fecha, el texto del artículo 157 del Código Tributario, producto de las sucesivas modificaciones normativas realizadas en su oportunidad por el Decreto Legislativo 953, la Ley 28365, el Decreto Legislativo 981 y el Decreto Legislativo 1121, se encuentra previsto en los términos siguientes:

\section{Artículo 157: DEMANDA CONTENCIOSO ADMINISTRATIVA \\ La resolución del Tribunal Fiscal agota la vía administrativa. Dicha resolución podrá impugnarse mediante el Proceso Contencioso Administrativo, el cual se regirá por las normas contenidas en el presente Código y, supletoriamente, por la Ley 27584 , Ley que regula el Proceso Contencioso Administrativo.}

La demanda podrá ser presentada por el deudor tributario ante la autoridad judicial competente, dentro del término de tres (3) meses computados a partir del día siguiente de efectuada la notificación de la resolución debiendo contener peticiones concretas.

La presentación de la demanda no interrumpe la ejecución de los actos o resoluciones de la Administración Tributaria.

La Administración Tributaria no tiene legitimidad para obrar activa. De modo excepcional, la Administración Tributaria podrá impugnar la resolución del Tribunal Fiscal que agota la vía

(58) En vigencia desde el 19 de julio de 2012

(59) Conforme al texto vigente del artículo 11 de la LPCA, la competencia funcional para conocer las demandas contenciosas administrativas interpuestas por la Administración Tributaria con motivo de la emisión de Resoluciones del Tribunal Fiscal, corresponde: (i) al Juez Especializado, en primera instancia; y, (ii) la Sala Especializada en lo Contencioso Administrativo, en segunda instancia. 
administrativa mediante el Proceso Contencioso Administrativo en los casos en que la resolución del Tribunal Fiscal incurra en alguna de las causales de nulidad previstas en el artículo 10 de la Ley 27444, Ley del Procedimiento Administrativo General.

En nuestra opinión, y sobre la base de su interpretación histórica, consideramos que los alcances de la legitimidad para obrar activa de la Administración Tributaria, debe ser interpretada a partir de lo previsto en el artículo 157 del Código Tributario, en los siguientes términos:

En primer lugar, el artículo 157 del Código Tributario es una disposición especial frente a lo previsto sobre la materia en la LPCA. Por tal motivo, el artículo 157 del Código Tributario se debe interpretar y aplicar en forma directa a fin de establecer los alcances de la legitimidad para obrar activa de la Administración Tributaria para impugnar una RTF. Solo en caso no se encuentre regulado algún aspecto sobre la materia en el artículo 157 del Código Tributario, se podrá aplicar en forma supletoria lo previsto en la LPCA, la LPAG y, de ser el caso, el Código Procesal Civil.

En segundo lugar, no queda duda que la Administración Tributaria puede impugnar válidamente una RTF mediante la interposición de la correspondiente demanda contenciosa administrativa. La regla general, desde el texto original del artículo 157 del Código Tributario y hasta la fecha, ha sido que la Administración Tributaria goce de legitimidad para obrar activa.

En tercer lugar, en cuanto a su naturaleza, la Administración Tributaria no goza de legitimidad para obrar activa ordinaria. Esto se debe a que la Administración Tributaria: (i) no es titular de la relación material involucrada, la cual le corresponde al acreedor tributario (ejemplo, el Gobierno Central); y, (ii) es un órgano de administración de tributos y derechos arancelarios. Esta situación se encuentra fuera de discusión a la fecha con motivo del reconocimiento expreso de tal situación en el cuarto párrafo del artículo 157 del Código Tributario.

En cuarto lugar, y derivado de lo anterior, la Administración Tributaria goza de una legitimidad para obrar activa extraordinaria. Es decir, aun cuando se reconoce que no es titular de la relación material involucrada, por ley se establece la posibilidad para que la Administración Tributaria pueda impugnar válidamente una RTF en la vía del proceso contencioso administrativo.

En quinto lugar, toda vez que la legitimidad para obrar activa de la Administración Tributaria es extraordinaria, los alcances de la ley de autorización correspondiente deben ser interpretados y aplicados en forma excepcional, taxativa y restrictiva.

En sexto lugar, los únicos supuestos en los que la Administración Tributaria puede impugnar una RTF en la vía del proceso contencioso administrativo, son los previstos en el artículo 10 de la LPAG. La excepción se encuentra constituida por la RTF que haya establecido jurisprudencia de observancia obligatoria.

En séptimo lugar, la configuración de las causales de nulidad previstas en el artículo 10 de la LPAG para que la Administración Tributaria impugne una RTF en la vía del proceso contencioso administrativo, debe ser manifiesta, insubsanable y trascendente. No es posible, vía la alegación de una nulidad prevista en el artículo 10 de la LPAG, que la Administración Tributaria pretenda cuestionar una diferencia de criterio con el Tribunal Fiscal en relación a la valoración de los medios probatorios o a la interpretación de las normas aplicables en el caso concreto. Estos supuestos no constituyen situaciones impugnables.

En octavo lugar, en función a la habilitación prevista en las causales previstas en el artículo 10 de la LPAG, la Administración Tributaria solo tiene la potestad de formular pretensiones de declaración de nulidad, conforme a lo previsto en el numeral 1 del artículo 5 de la LPCA. Por tanto, la Administración Tributaria no tiene habilitación legal, específica y expresa, para formular pretensiones de plena jurisdicción, conforme lo previsto en el numeral 2 del artículo 5 de la LPCA.

En noveno lugar, no es posible alegar la aplicación del artículo 13 de la LPCA, para extender los alcances de la legitimidad para obrar activa de la Administración Tributaria, prevista en el artículo 157 del Código Tributaria. No es aplicable, porque: (i) el primer párrafo del artículo 13 de la LPCA solo es aplicable para quien alegar ser titular de la relación material involucrada, situación que no es el caso de la Administración Tributaria; y, (ii) el segundo párrafo del artículo 13 de la LPCA solo es aplicable para los supuestos de procesos de lesividad, situación que no es el caso de la Administración Tributaria, porque no existe identidad entre la entidad que emite el acto administrativo (Tribunal Fiscal) y la entidad que impugna el mismo acto en la vía judicial (la Administración Tributaria).

\section{Conclusiones}

A partir de lo expuesto, referenciado y desarrollado a lo largo del presente trabajo, 
consideramos pertinente formular las siguientes conclusiones:

- La Administración Tributaria, no queda duda, tiene la potestad para impugnar válidamente una RTF en la vía judicial, mediante la interposición de la correspondiente demanda contenciosa administrativa.

- Los alcances de la potestad de la Administración Tributaria para impugnar una RTF en la vía judicial, están sujetos a lo previsto específica y expresamente en la ley. Tratándose de una autorización excepcional para tal efecto, los alcances de la ley de autorización correspondiente deben ser interpretados y aplicados en forma excepcional, taxativa y restrictiva.

- Los únicos supuestos en los que la Administración Tributaria puede impugnar una RTF en la vía del proceso contencioso administrativo, son los previstos en el artículo 10 de la LPAG.

- No constituye una causal válida de impugnación de una RTF, la diferencia de criterio con el Tribunal Fiscal en relación a la valoración de los medios probatorios o a la interpretación de las normas aplicables en el caso concreto.

- La Administración Tributaria solo tiene la potestad de formular pretensiones de declaración de nulidad. No tiene habilitación legal, específica y expresa, para formular pretensiones de plena jurisdicción. Cualquier situación para lograr en forma indirecta esta situación, se encuentra prohibida a la fecha.

\section{Referencias bibliográficas}

Danós, J. (2000). El proceso contencioso administrativo en materia tributaria. Themis. Revista de Derecho, 41, 73-95. https://revistas. pucp.edu.pe/index.php/themis/article/view/11653

Dromi, R. (1999). El procedimiento administrativo. Ciudad Argentina.
Escribano, F. (2009). La configuración jurídica del deber de contribuir. Perfiles Constitucionales. Grijley.

Espinosa-Saldaña, E. (2003). El nuevo proceso contencioso administrativo peruano: ¿Principio del fin de nuestro amparo alternativo? En Jurisdicción constitucional, Impartición de Justicia y Debido Proceso. ARA Editores.

Fernández, M. (1995). La autoliquidación tributaria. Instituto de Estudios Fiscales-Marcial Pons.

García, C. (2000). El principio de seguridad jurídica en materia tributaria. Marcial Pons.

García, F. (2001). Derechos y garantías constitucionales en los procedimientos tributarios. Situación actual y perspectivas de evolución. En F. Escribano (ed.), Derecho Financiero Constitucional (pp. 265-306). Civitas Ediciones.

García, J. (1998). Una nueva Ley General Tributaria. Problemas constitucionales. En P. Kirchhof, J. Cardoso, A. Di Pietro, J. García \& A. Rodríguez, Garantías constitucionales del contribuyente (pp. 213236). Tirant Lo Blanch.

Gonzáles, J. (2001). Manual de Derecho Procesal Administrativo (3. ${ }^{\text {a }}$ ed.). Civitas.

Huapaya, R. (2006). Tratado del Proceso Contencioso-Administrativo. Jurista Editores.

Huapaya, R. (2010). Algunos temas puntuales en relación a la regulación normativa del proceso contencioso-administrativo de "agravio" o de lesividad en la Ley que regula el Proceso Contencioso Administrativo del Perú. Revista Institucional AMAG. Academia de la Magistratura, 1(9), 87-103. http://repositorio.amag.edu.pe/ handle/123456789/223.

Malvarez, L. (2001). La función tributaria en el marco del Estado Social y Democrático de Derecho. Revista española de Derecho Financiero, 109-110, 377-438.

Monroy, J. (2004). La Formación del Proceso Civil Peruano (escritos reunidos) (2. ${ }^{\text {a }}$ ed.). Palestra Editores.

Morón, J. (2015). El proceso contencioso de lesividad: catorce años después de su incorporación en el derecho peruano. IUS ET VERITAS, 51, 224-246. https://revistas.pucp.edu.pe/index.php/iusetveritas/article/ view/15660/16097.

Priori, G. (2002). Comentarios a la Ley del Proceso Contencioso

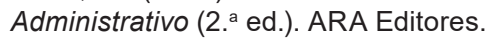

Robles, C., Ruiz de Castilla, F. \& Villanueva, W. (2009). Código Tributario. Doctrina y Comentarios. Instituto Pacífico.

Smith, A. (2012). Investigación sobre la naturaleza y causas de la riqueza de las naciones. (G. Franco, trad.). Omegalfa.

Tribunal Constitucional del Perú. (2004, 28 de junio). Expediente No. 3548-2003-AA/TC. https://www.tc.gob.pe/jurisprudencia/2005/035482003-AA.html (10) 